\title{
COVID Key: A Multifunctional Device to Avoid Touch
}

\author{
Pushkar Kamble $^{1}$ (1) $\cdot$ Yash G. Mittal $^{1} \cdot$ Gopal Gote $^{1} \cdot$ Rajendra Hodgir $^{1} \cdot$ K. P. Karunakaran ${ }^{1}$
}

Received: 25 May 2021 / Accepted: 1 July 2021 / Published online: 9 July 2021

(c) Indian National Academy of Engineering 2021

\begin{abstract}
COVID-19 is a global pandemic caused by the novel coronavirus. Although the surfaces pose a low risk of transmission, it is beneficial to use a handheld key-like device to avoid touching the surfaces, especially in public places. The present article reveals a novel design for a multifunctional handheld device, termed the COVID key. The proposed COVID key exhibits ten distinct features, viz. doorknob opener, pushing, pulling, forceps action, sharp edge, key chain, smartphone stand, and a linear and angular scale frequently used in daily life. Theoretical and computational analyses are carried out to check the validity of the design under different loading conditions resembling everyday use. Topological optimization is carried out to achieve the best stiffness-to-weight ratio. The final design is 3D printed in two different materials, ABS (acrylonitrile-butadiene-styrene) and PLA (poly-lactic-acid), using fused deposition based additive manufacturing. Testing and validation of the design are carried out with everyday actions. The COVID keys are distributed among a group of ten unbiased users. The user satisfaction score is recorded based on six basic metrics, viz. ease of use, size, strength, appearance, material and ease of carrying. A satisfaction score of $85 \%$ is reported, with ABS being the preferred material of choice.
\end{abstract}

Keywords COVID-19 Contaminated Surfaces $\cdot$ Additive Manufacturing $\cdot$ COVID device $\cdot$ FEA $\cdot$ Optimization

\section{Introduction}

First reported in Wuhan, China, in late 2019, COVID-19 is a global pandemic now. The virus that causes COVID19 belongs to a group of zoonotic viruses termed coronavirus. The present virus responsible for COVID-19 is termed severe acute respiratory syndrome coronavirus 2 (SARSCoV-2) (Wang et al. 2020). The virus transmission occurs through respiratory droplets of saliva and sputum generated while speaking, coughing, and sneezing (WHO 2020). The droplets generated from sneezing travel a longer distance of 7-8 $\mathrm{m}$ (Bourouiba 2020). When they fall on the surfaces, the drying time of the droplets varies from 5 to $70 \mathrm{~s}$ on various surfaces under various conditions (Bhardwaj and Agrawal 2020). Infected surfaces, therefore, is an indirect route of transmission (WHO 2020). If a person touches the surfaces with the active virus by hands and then touches their ophthalmic or nasal mucosae, the infection gets transmitted. Although it is recently found that transmission from

Pushkar Kamble

pushkarkamble@gmail.com

1 Indian Institute of Technology Bombay, Powai, Mumbai 400076, India contaminated surfaces in the public setting is low, it is important to avoid direct contact with the surfaces at specific locations with a high number of individuals living with COVID-19, such as hospitals and quarantine centres. One solution for this problem is to use a handheld device that helps perform various actions involving a direct touch of the surfaces.

Several devices were recently launched in the market, colloquially known as "COVID Key" or "COVID Key Chain". The detailed survey of the existing designs of the keys reveals a universal form of the key, as shown in Fig. 1. There are several other actions that the available keys do not provide, such as rotation of the taps, bottle opener, holding currency notes, etc. For these actions, a key is required that incorporates most of the day-to-day activities involving touch. In the present article, a handheld key-like device is proposed for various actions such as pinching, pulling, rotating, etc. The detailed use of the device is discussed subsequently. The size and shape of the key can be customized to suit the individual ergonomic needs. Hence, 3D printing is the most suitable route for mass customized production.

Various actions that involve touching the surfaces are pinching, pulling, pushing, rotating, and lifting. Pinching action is required while handling thin objects such as papers, 


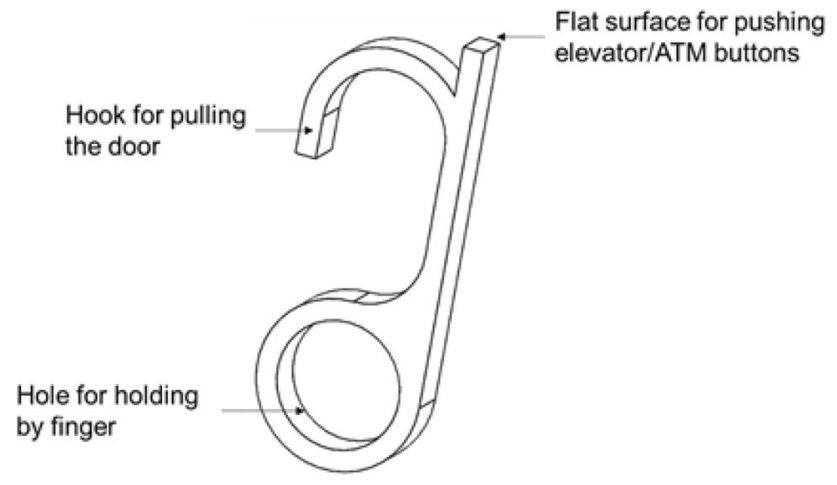

Fig. 1 Generic COVID Key

plastic sheets, and currency notes. Since many people handle the currency and majority of papers in the office setting, it increases the transmission risk. A heavy number of people commonly touches door handles. Keeping the doors always open could be one solution, but that may not be an option in the rooms with an air conditioner or air purifiers. Thus, pulling the handles of the door, drawers, trolleys pose a greater risk of transmission. Pushing is another action essentially performed with doors, windows, chairs, etc. Rotation/Gyration is an action performed while opening/closing the taps, knobs of the electrical instrument, opening the threaded bottle caps. Lifting objects such as plastic bags, etc., is another common action performed in the social setting, especially at the supermarkets. All the actions mentioned above increase the touching of surfaces repeatedly. A handheld device that can assist in avoiding the repeated touching of the surfaces
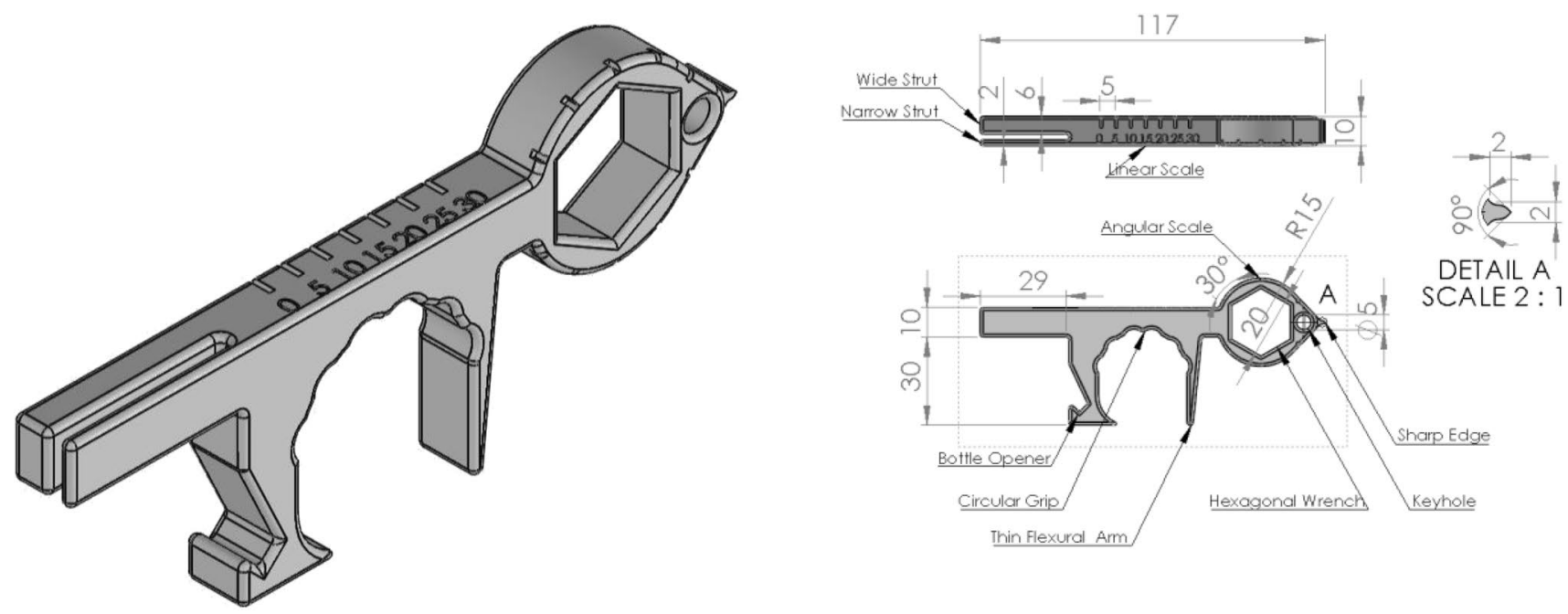

(b) at public places is a prime need in environments with active contagions.

In these actions mentioned above, the ergonomics of the action is crucial to notice. The key needs to have a firm grip by hand and sufficiently rigid to sustain the loads generated by the actions. The design of the key for different functions is discussed in the subsequent sections.

\section{Design and features}

The proposed COVID key is designed with a minimalistic design and maximum features approach (Fig. 2). The overall length and breadth of the key are limited to $117 \mathrm{~mm}$ and $50 \mathrm{~mm}$, respectively, and the thickness is set to $10 \mathrm{~mm}$ to avoid discomfort while carrying it in the pocket.

The design parameters are selected to provide multiple distinct features for everyday use. A wide strut is provided at the front of the key for pushing operations, such as pressing the elevator buttons (Fig. 2). A thin, flexible narrow strut accompanying the main strut enables the forceps-like action to pick up papers or currency notes. Facial masks act as a barrier to protect the nose and mouth, reducing the probability of contacting the virus. Handling the outside of the facial masks with bare hands is not recommended. The forcepslike feature of the proposed COVID key helps remove or temporary lowering face masks.

The proposed COVID key has graduation marks on the lateral side for linear measurements up to $30 \mathrm{~mm}$ with the least count of $5 \mathrm{~mm}$. Additionally, the circular surface has graduation marks for angular measurements up to $360^{\circ}$ at

(a)

Fig. 2 a CAD model of the COVID key, b labels and dimensions of the COVID key 
intervals of $30^{\circ}$. The hole is made hexagonal to enable the wrench-like feature to tighten/loosen the hex bolts. The hole is made finger-sized that enables a good grip for holding the key between fingers. A smaller hole near the wrench feature helps fasten the car keys. The sharp edge helps tear and screw operations. Below the struts, there is a perpendicular arm with a notch that acts as a bottle opener. The other side of this arm can be used for pulling/lifting actions. Near to this arm is a circular grip for holding and operating doorknobs or circular headed taps. A thin, flexible element is present besides the grip makes it adjustable. Figure 2 shows the CAD (computer-aided design) model of the proposed design along with a labelled diagram highlighting different dimensions and features.

\section{Analysis}

Different structural analyses followed by computational (FEA) evaluation are performed under static loading conditions on the various features presented in the COVID key design. The designed object is considered a solid body, following linear isotropic behaviour and uniform loading conditions. The design is made for an upper limit of $100 \mathrm{~N}$, set as the average human values of force (Nilsen et al. 2012). The design and FEA validation are done using SOLIDWORKS 2019 Educational License. The final design is 3D printed using the fused deposition modelling (FDM) technique. ABS and PLA are some of the most commonly used materials for FDM 3D printing (Mazzanti et al. 2019). In this work, a functional prototype is analyzed and fabricated using both materials.

\section{Buckling and Compression Analysis}

The wide strut is used for pushing actions, undergoing buckling conditions. Euler's theory of buckling is applied with the following assumptions (Stephen and Timoshenko 1961):

1. The column is initially perfectly straight and is axially loaded, with a maximum force of $100 \mathrm{~N}$.

2. The section of the column is uniform. The end curvature effect of fillets is neglected.

3. The column is perfectly elastic, homogeneous and isotropic and obeys Hooke's Law.

4. The column length $(L=30 \mathrm{~mm})$ is substantial compared to the lateral dimensions $(6 \mathrm{~mm} \times 10 \mathrm{~mm})$.

5. The direct stress is minimal compared with the bending stress corresponding to the buckling condition.

6. The self-weight of the column is neglected.

7. The column is failing by buckling only.
A fixed-free buckling condition is employed for the case. The slenderness ratio $(\lambda)$ is calculated using the relation mentioned in Eq. (1)as follows:

$\lambda=\frac{L_{e}}{r_{k}}$,

where $L_{e}$ is the effective length of the column $(=2 L$, for fixed-free condition) and $r_{k}$ is the radius of gyration corresponding to the critical area moment of inertia $\left(r_{k}=\sqrt{\frac{I}{A}}\right.$; $I=\frac{d \cdot b^{3}}{12} ; b=6 \mathrm{~mm}$ (width), $d=10 \mathrm{~mm}$ (depth); $A$ is the crosssectional area of the column). The slenderness ratio comes out to be 34.62, referring to an intermediate column buckling condition. The corresponding critical buckling load $\left(P_{c r}\right)$ is calculated using Eq. 2 as fpllows:

$P_{c r}=\frac{\pi^{2} E . I}{4 L^{2}}$,

where $E$ is the modulus of linear elasticity for ABS (2.5 GPa (Vácha and Borůvka 2015)) and PLA (2.78 GPa (Wittbrodt and Pearce 2015)), The corresponding critical buckling loads $\left(P_{c r}\right)$ are $1.26 \mathrm{kN}$ and $1.4 \mathrm{kN}$ for ABS and PLA, respectively. The critical buckling loads hugely surpass the maximum applied axial load, indicating that design is safe under buckling condition for both the materials, as follows:

$P_{c r}(1260(\mathrm{ABS}), 1400(\mathrm{PLA}))>P_{\text {applied }}(100 \mathrm{~N})$

FEA validation is done by fixing the nearest flat face parallel to the cross-section in the hexagonal wrench region. A direct axial compressive load of $100 \mathrm{~N}$ is applied on the face of the wide strut, as shown in Fig. $3 \mathrm{a}$.

The study consisted of solid mesh, single-mode, FFEPlus buckling analysis with zero strain temperature as 298 K. ABS material with a linear elastic isotropic model is selected from the software database, with the material properties as mentioned in Table 1. PLA material is not available in the database. It is inserted as a new material with the required mechanical properties defined, also mentioned in Table 1.

The solid mesh type is used. The element size and tolerance are $2.45535 \mathrm{~mm}$ and $0.122768 \mathrm{~mm}$, respectively. The mesh quality plot is set to high, and the meshed profile is shown in Fig. 3b. The total number of nodes and elements formed are 25,053 and 14,715, respectively, with the maximum aspect ratio of 20.14 . Almost $87 \%$ of elements have an aspect ratio less than 3 , and around $0.2 \%$ of elements have an aspect ratio greater than 10 . The same set of computational environments is applied to every simulation.

The result of the buckling analysis shows the amplitude plot, with a maximum amplitude of 0.025 for both the cases as depicted in Fig. 3c and d. The similarity in 


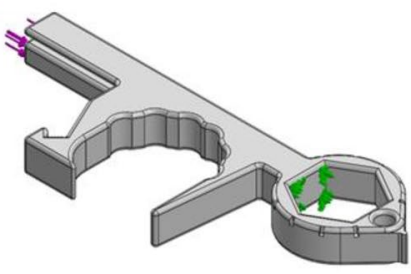

1

(a)

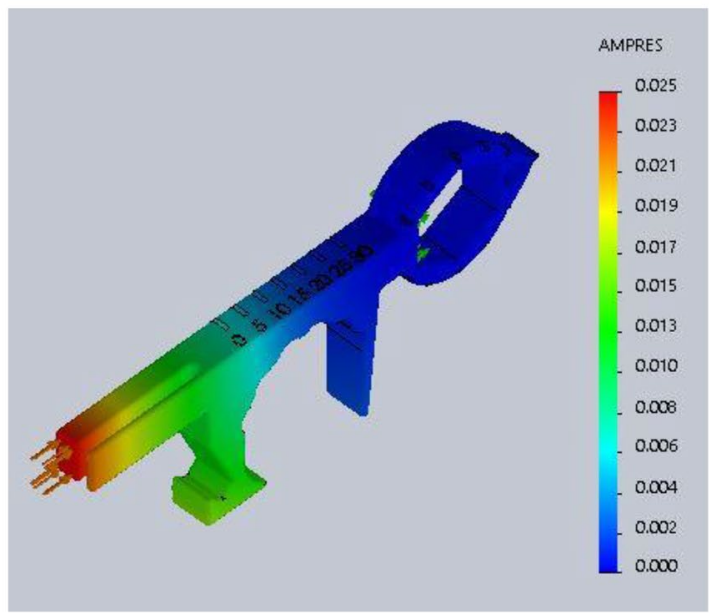

(c)

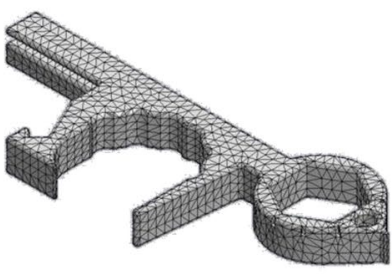

L.

(b)

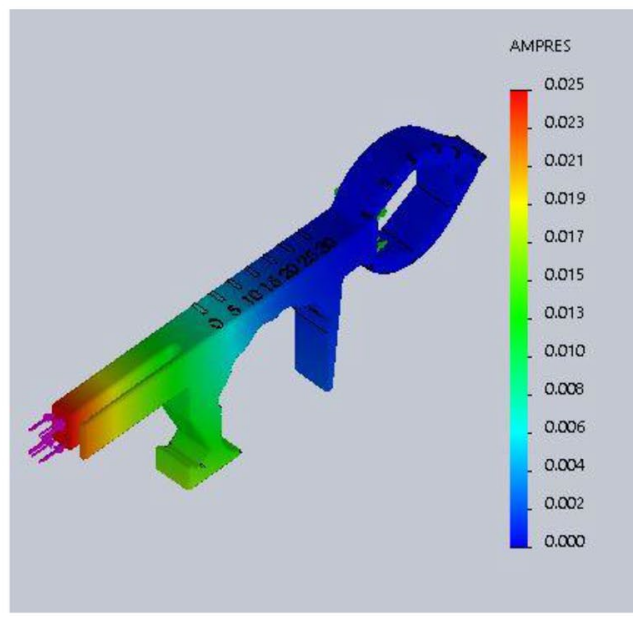

(d)

Fig. 3 Buckling analysis: a fixture geometry and applied load; b meshed body; c amplitude results (ABS); d amplitude results (PLA)

Table 1 Material properties of ABS and PLA

\begin{tabular}{lll}
\hline Mechanical property & ABS & PLA \\
\hline Tensile strength & $30 \mathrm{MPa}$ & $54 \mathrm{MPa}$ (Wittbrodt and Pearce 2015; \\
& & Ferreira et al. 2017) \\
Compressive strength & - & $100 \mathrm{MPa}$ (Song et al. 2017) \\
Shear strength & $17 \mathrm{MPa}$ (Cantrell et al. 2017) & $42.15 \mathrm{MPa}$ (Torres et al. 2015) \\
Yield strength & $48.3 \mathrm{MPa}$ (Banjanin et al. 2018) & $50.5 \mathrm{MPa}$ (Wittbrodt and Pearce 2015) \\
Mass density & $1020 \mathrm{~kg} / \mathrm{m}^{3}$ & $1320 \mathrm{~kg} / \mathrm{m}^{3}$ (Grassia et al. 2011) \\
Elastic modulus & $2 \mathrm{GPa}$ & $2.78 \mathrm{GPa}$ (Wittbrodt and Pearce 2015) \\
Poisson's ratio & 0.394 & 0.328 (Ferreira et al. 2017) \\
Shear modulus & $318.9 \mathrm{MPa}$ & $1092 \mathrm{MPa}$ (Ferreira et al. 2017) \\
\hline
\end{tabular}

the amplitude for both the materials can be attributed to the fact that the applied load is much less than the critical buckling load for both cases.

Under a similar set of conditions, a uniaxial compression analysis is also done. The maximum Von-Mises stress developed in the strut for ABS and PLA is $1.55 \mathrm{MPa}$ 6.245 $\mathrm{MPa}$ respectively (Fig. 4a and b). The factor of safety for ABS and PLA is 19.35 and 8.65 respectively. The corresponding freeend deflection and maximum strain for ABS are $0.4628 \mathrm{~mm}$ and $1.094 \times 10^{-3} \mathrm{~mm} / \mathrm{mm}$ respectively, as shown in Fig. $4 \mathrm{c}$ and e. For PLA, it is $0.3337 \mathrm{~mm}$ and $1.401 \times 10^{-3} \mathrm{~mm} / \mathrm{mm}$, respectively (Fig. 4d and f). 


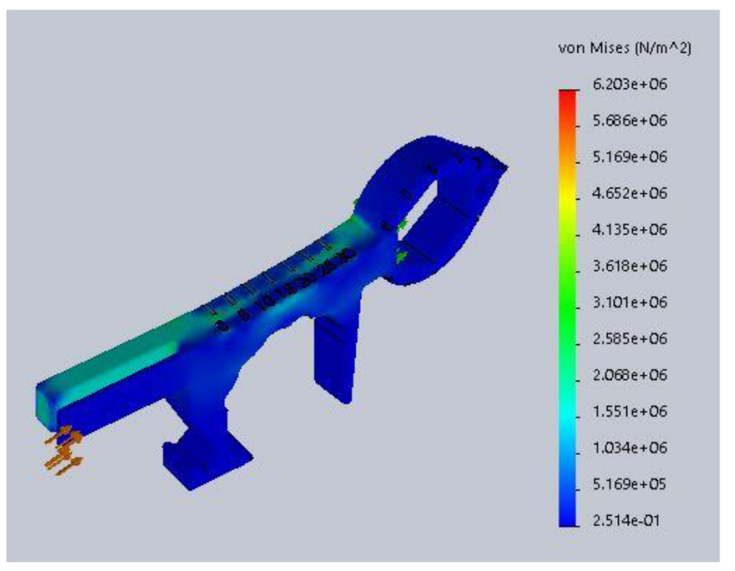

(a)

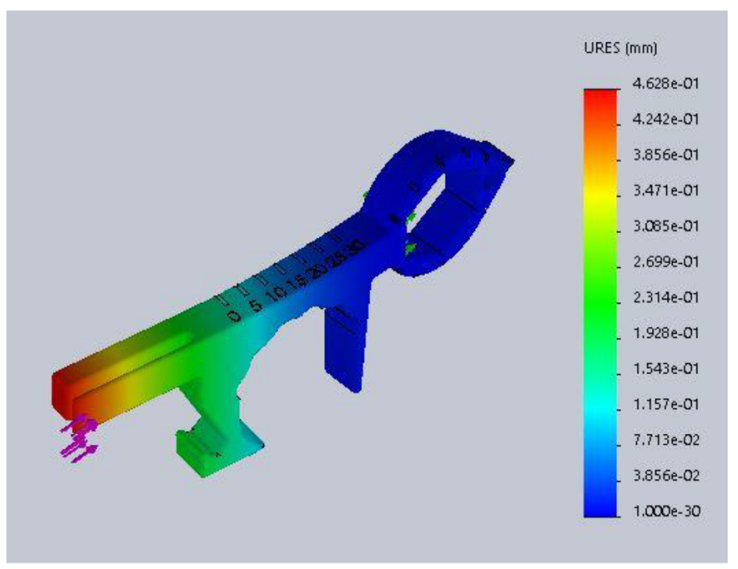

(c)

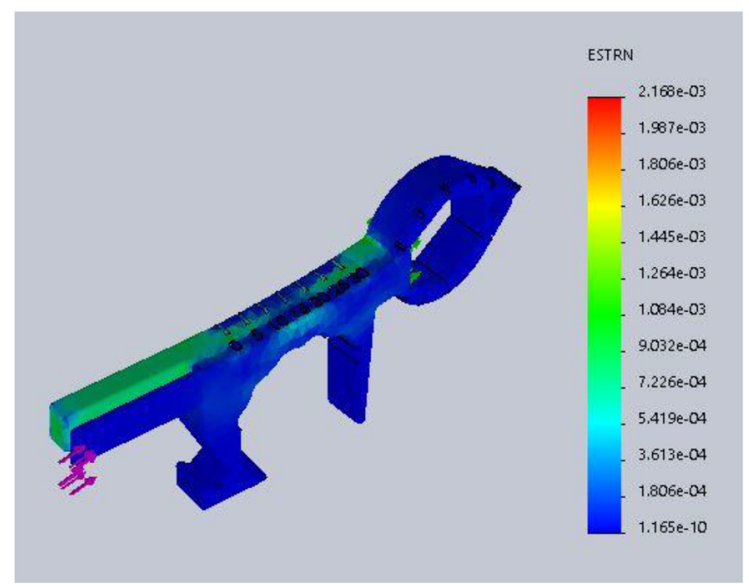

(e)

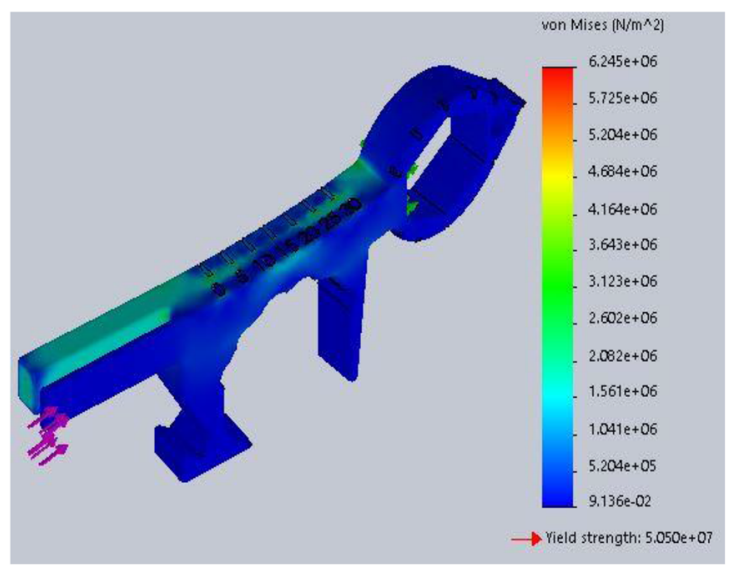

(b)

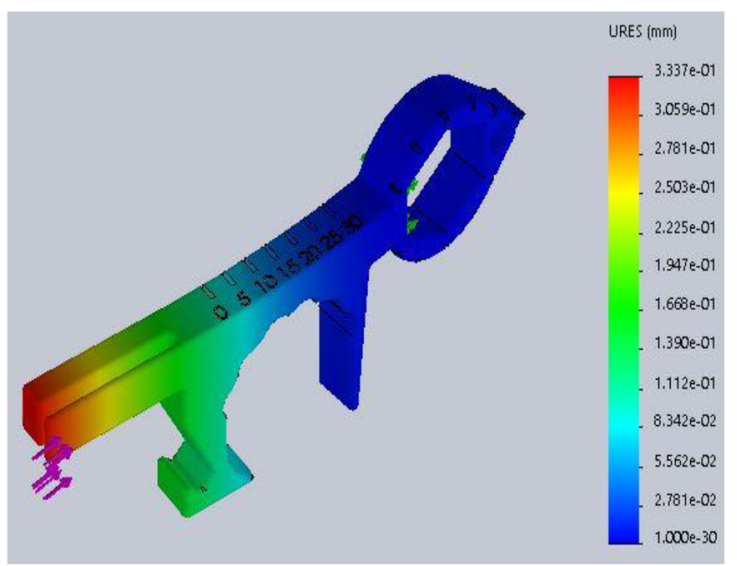

(d)

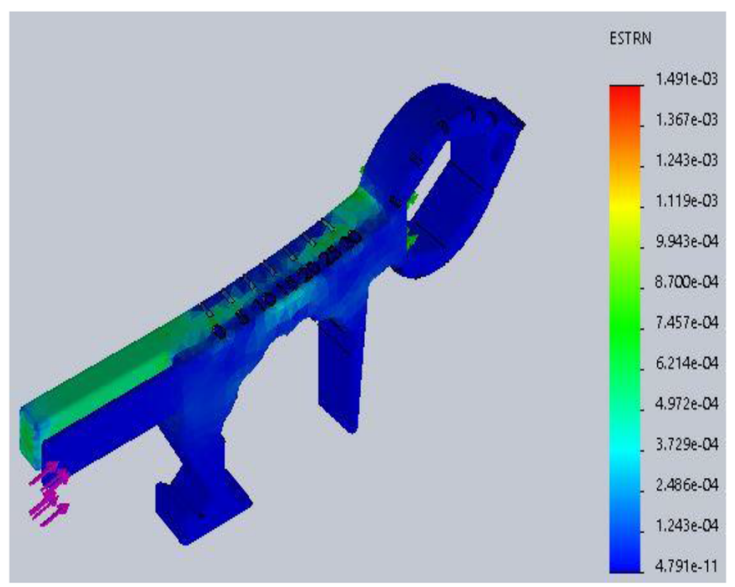

(f)

Fig. 4 Compression analysis: ABS: a von-mises stress; $\mathbf{c}$ deflection; e principal strain; PLA: $\mathbf{b}$ von-mises stress; $\mathbf{d}$ deflection; $\mathbf{f}$ principal strain 


\section{Bending analysis}

The COVID key design presents various features that undergo direct or indirect bending, for example, flexion of the narrow strut for forceps feature, bottle-cap opening action, pulling action using the rear side of the bottle opener, bending of the thin flexural arm near the hexagonal wrench feature, for the doorknob action. All the bending conditions are cantilevers, and Euler-Bernoulli beam bending theory is applied with the following assumptions (Richard and Budynas 2011):

1. The material of the beam is homogeneous and isotropic.

2. The value of Young's Modulus of Elasticity is the same in tension and compression.

3. The transverse sections, which were plane before bending, remain plane after bending also.

4. The beam is initially straight, and all longitudinal filaments bend into circular arcs with a common centre of curvature.

5. The radius of curvature is large as compared to the dimensions of the cross-section. The effect of end-fillets and stress concentrations is also neglected.

6. Each layer of the beam is free to expand or contract, independently of the layer above or below it.

The narrow strut can be pushed down to hold delicate features like paper, laminates, and coins. As mentioned earlier, it can also be used to temporarily lower the face mask as and when needed without using the fingers, enhancing the health and safety of the user. The clearance between the struts restricts the maximum deflection $(\delta)$ up to $2 \mathrm{~mm}$ only. Assuming the Euler-Bernoulli cantilever beam bending, the load $(P)$ required to generate this amount of deflection can be calculated using Eq. (4).

$P=\frac{3 \delta E_{b} \cdot I}{L^{3}}$

The length of the section $(L)$ is considered to be $30 \mathrm{~mm}$, and the moment of inertia $(I)$ is calculated for the rectangular section $\left(I=\frac{d \cdot b^{3}}{12} ; b=\mathrm{w} \mathrm{mm}\right.$ (width), $d=10 \mathrm{~mm}$ (depth)). With $E_{b}$ as the bending modulus (2.10 GPa for ABS (Stephen and Timoshenko 1961) and 0.973 GPa for PLA (Abeykoon et al. 2020)), the lateral load required is $2.711 \mathrm{~N}$ for $\mathrm{ABS}$ and $1.256 \mathrm{~N}$ for PLA. The corresponding bending stresses for ABS and PLA are 12.19 MPa and 5.67 MPa, respectively, which are significantly less than the tensile strength of the respective materials, indicating that the deflection is in elastic range and the narrow strut is going to restore to its original position once the load is removed, for both the materials.

Validation of the design feature based on the above bending analysis is done using FEA. The rear face of the COVID key is treated as a fixture, and an axially perpendicular load of roughly $3 \mathrm{~N}$ for ABS and $1.26 \mathrm{~N}$ for PLA is applied at the free end of the narrow strut.

The free tip of the narrow strut is showing a deflection of $2.188 \mathrm{~mm}$ for ABS and $1.943 \mathrm{~mm}$ for PLA (Fig. 5a and b) and the maximum bending stress detected is $14.31 \mathrm{MPa}$ (ABS) and 6.12 MPa (PLA), at the fixed end. Compared with the analytical solutions, the slight discrepancies in these values can be attributed to simplifying the complex geometry and ignoring attributes like fillets and curvatures in the calculations.

Below the forceps feature, the bottle opener is appropriate for metallic caps, usually placed over cold drinks and

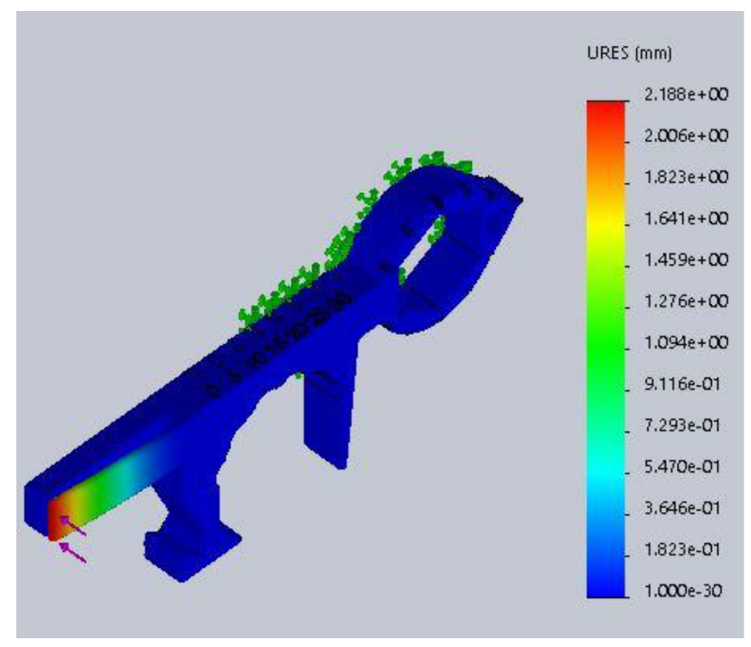

(a)

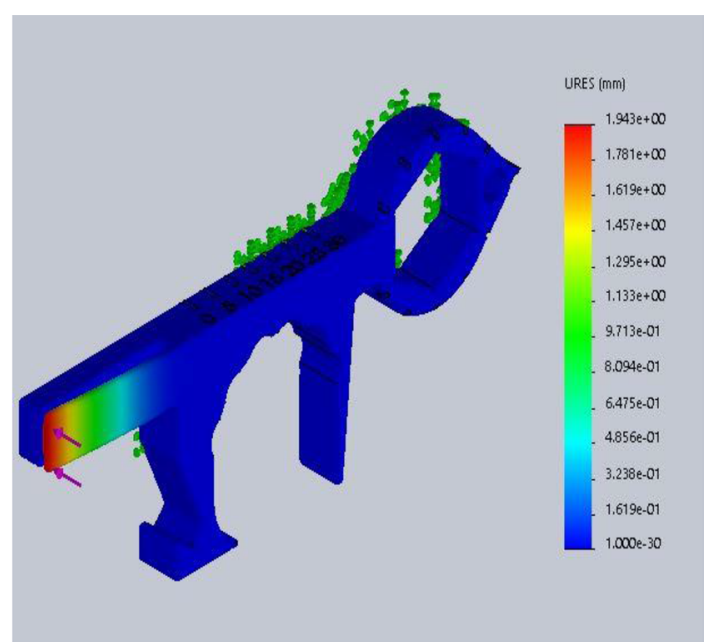

(b)

Fig. 5 Displacement of the free tip of the narrow strut under forceps action, a ABS, b PLA 
beverage bottles. On close inspection, it can be seen that the bottle opener arm, during the action, acts as a cantilever beam, subjected to a moment at the free end. The COVID key marks a two-point contact with the bottle cap, one with the bottle opener feature itself and the other with the struts to use the inbuilt bottle opener. To operate, the COVID key is fixed under the cap, pushed upwards from the wrench area and undergoes a pure rotation along with the point of contact with the struts, as shown in Fig. $6 \mathrm{a}$.

It is found that a moment of $12 \mathrm{lbs}-\mathrm{in}(1.356 \mathrm{Nm})$ is enough to open the cap of a bottle of beer (Jean-Philippe and Clerc 2002). Therefore, the pulling force, $F$, acting at a perpendicular distance, $r \sim 25 \mathrm{~mm}$, required for this action, is $55 \mathrm{~N}\left(\frac{1.356}{0.025}\right)$ only. The thinnest section in this feature is $10 \mathrm{~mm}$ wide and $5 \mathrm{~mm}$ thick. The corresponding bending stress has a peak value of $26.032 \mathrm{MPa}$ in this section.

FEA validation is done by fixing the appropriate sections and applying the calculated moment of $1.356 \mathrm{Nm}$ over the wrench area. The results showed a maximum displacement of about $3 \mathrm{~mm}$ for ABS and about $2.192 \mathrm{~mm}$ for PLA, at the very end, near the sharp edge of the COVID key. The maximum stress recorded is $27.17 \mathrm{MPa}$ (ABS) and $27.66 \mathrm{MPa}$ (PLA). The underlying plots of bending stress and displacement for both the materials are shown in Fig. 6b-e.

Another element that undergoes pure bending is the thin flexural arm that can be primarily used for holding cylindri$\mathrm{cal} / \mathrm{spherical}$ entities such as doorknobs. A transverse force $(F)$ is applied that elastically deforms the flexural arm to encapsulate the cylindrical/spherical entity for actions such as doorknobs and tap handles, as shown in Fig. 7.

The flexural arm is oriented in a non-prismatic manner, w.r.t. the direction of the force. The cross-sectional area (and the area moment of inertia), measured along the plane parallel to the force, changes along the axial length of the arm. The deflection $(y)$ of the arm (considered to be a cantilever beam) as a function of linear distance from the free end $(x)$ is calculated by solving the second-order homogeneous differential equation, as follows:

$E_{b} \cdot I_{x} \cdot \frac{d^{2} y}{d x^{2}}+F \cdot x=0$

where $I_{x}$ is the area moment of inertia at a given distance, $(\mathrm{x})$, from the free end of the arm. The depth of section $(b)$ is constant $(10 \mathrm{~mm})$ while the width $(d)$ linearly varies from a maximum, $d_{1}=3.22 \mathrm{~mm}$, at the fixed end to the minimum $d_{2}=2 \mathrm{~mm}$. Therefore, the area moment of inertia at a given section can be calculated using Eq. 6.

$I_{x}=\frac{b}{12}\left[\frac{d_{1} x+d_{2}(L-x)}{L}\right]^{3}$

Equation (5) then simplifies to Eq. (7). $\frac{d^{2} y}{d x^{2}}=\frac{-12 \cdot F \cdot L^{3} \cdot x}{E_{b} \cdot b \cdot\left[x \cdot\left(d_{1}-d_{2}\right)+d_{2} \cdot L\right]^{3}}=\frac{A \cdot x}{(B \cdot x+C)^{3}}$,

where $A=\frac{-12 \cdot F \cdot L^{3}}{E_{b} \cdot b}, B=d_{1}-d_{2}$ and $C=d_{2} . L$. Solving Eq. (7) yields the solution for free-tip deflection given by Eq. (8) as follows:

$y_{\max }=y(0)=\frac{A}{B^{3}}\left[\ln \left(1+\frac{B \cdot L}{C}\right)-\frac{1}{2}\left(\frac{3 \cdot B^{2} \cdot L^{2}+2 \cdot B \cdot C \cdot L}{(B \cdot L+C)^{2}}\right)\right]$

Substituting the value of $A$ in Eq. (8) and solving for $F$ yields Eq. (9).

$F=\frac{-B^{3} \cdot y_{\max } \cdot E_{b} \cdot b}{12 \cdot L^{3}\left[\ln \left(1+\frac{B \cdot L}{C}\right)-\frac{1}{2}\left(\frac{3 \cdot B^{2} \cdot L^{2}+2 . B . C . L}{(B . L+C)^{2}}\right)\right]}$

The negative sign in the expression mentioned in Eq. (9) denotes that by limiting the maximum deflection, $y_{\max }$ to $3 \mathrm{~mm}$ (10\% of the maximum knob diameter permissible in this design, i.e. $30 \mathrm{~mm}$ ), the force requirement comes out to be $36 \mathrm{~N}$ for ABS and $16.7 \mathrm{~N}$ for PLA. The maximum bending stress $\left(\sigma_{b(\max )}\right)$ generated at the fixed end can then be calculated using Eq. (10):

$\sigma_{b(\max )}=\frac{6 . F \cdot L}{b \cdot d_{1}^{2}}=43.42 \mathrm{MPa}(\mathrm{ABS}), 20 \mathrm{MPa}(\mathrm{PLA})$

FEA simulation is done for the validation of bending analysis of the thin flexural arm. The top face of the COVID key is chosen as a fixture, and a lateral force of $36 \mathrm{~N}$ for ABS and $16.7 \mathrm{~N}$ for PLA is applied in the negative $(y)$ direction (refer to Fig. 7 for the coordinate system) the free end of the arm. A maximum deflection of $2.869 \mathrm{~mm}$ and maximum bending stress of $47.33 \mathrm{MPa}$ are detected for ABS at the free-end and fixed-end. For PLA, $2.681 \mathrm{~mm}$ and $21.86 \mathrm{MPa}$ is observed. Figure 8 shows the graphical representation of the same. The measured and calculated values of stress are under the yield strength of the respective materials. Hence, the design is safe and is under the elastic recoil limit for both materials.

The last element/feature to show bending based deflection is the pull feature used for applications like a door opener. Like the doorknob feature, the suitable door handle is placed behind the bottle-opener arm, from where it is pulled, by holding the key using the wrench feature hole. The pulling force is acted upon the rear side, approximately midway of the bottle-opener arm. This eccentricity of force generates a bending moment along the length of the COVID key. The thinnest cross-section is in the middle of the doorknob feature with a thickness of $8 \mathrm{~mm}$. The section experiences a combined loading of axial force and bending stress. The maximum stress $\left(\sigma_{(\max )}\right)$ is given as follows: 


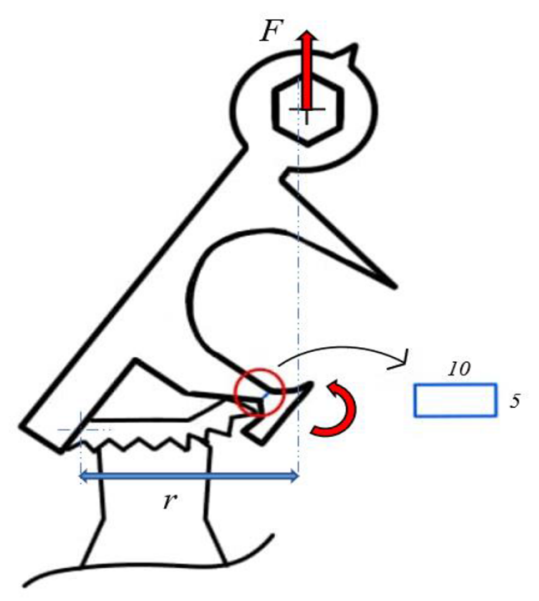

(a)

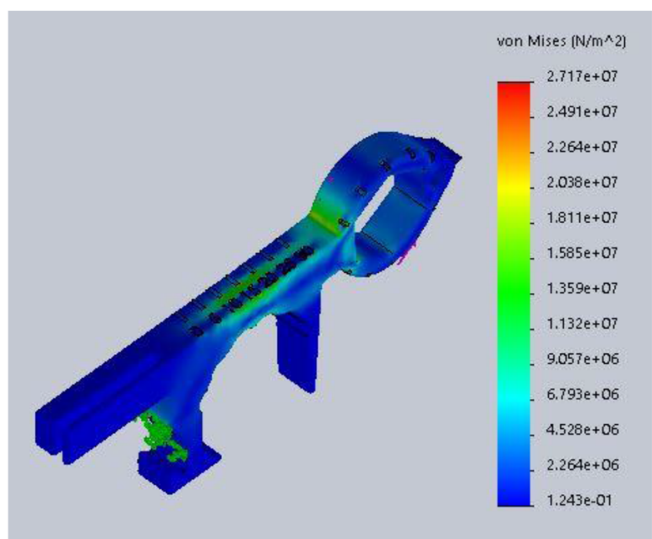

(b)

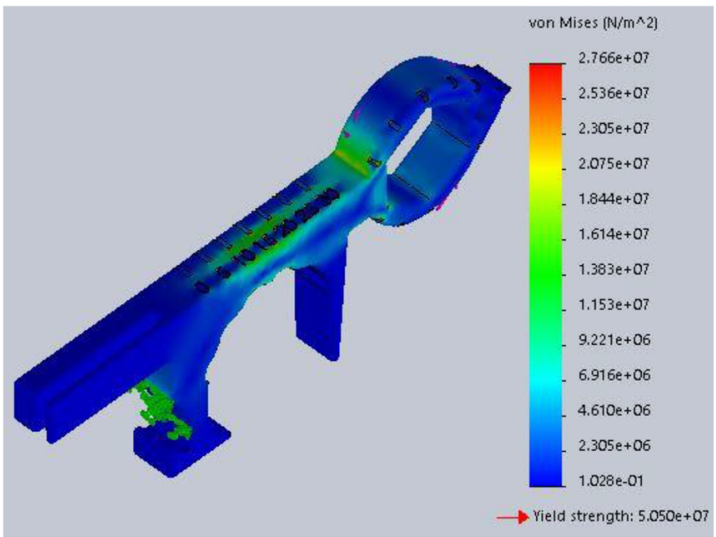

(d)

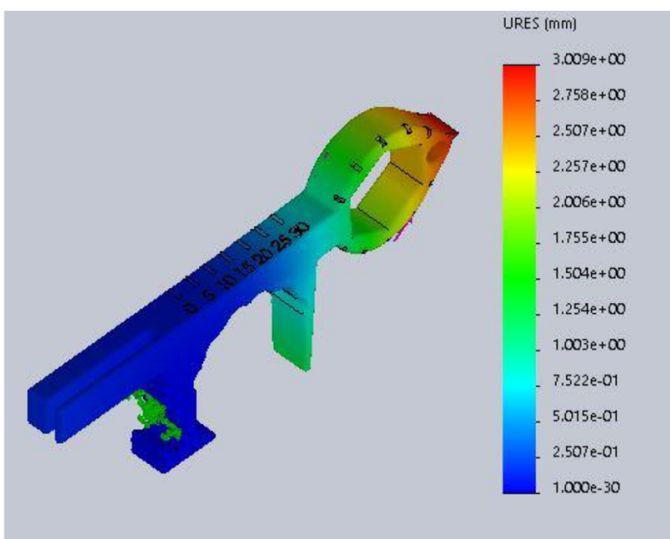

(c)

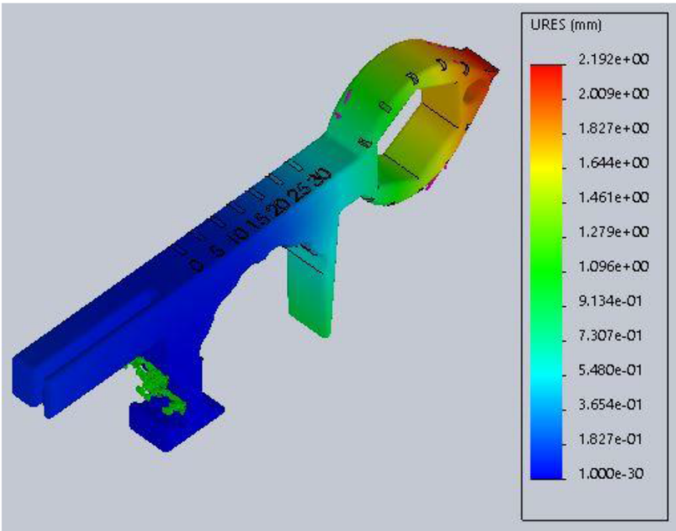

(e)

Fig. 6 Bottle opener feature of COVID key: a schematic of operation, b principal stress distribution (ABS), c displacement plot (ABS), d principal stress distribution (PLA), e displacement plot (PLA) 


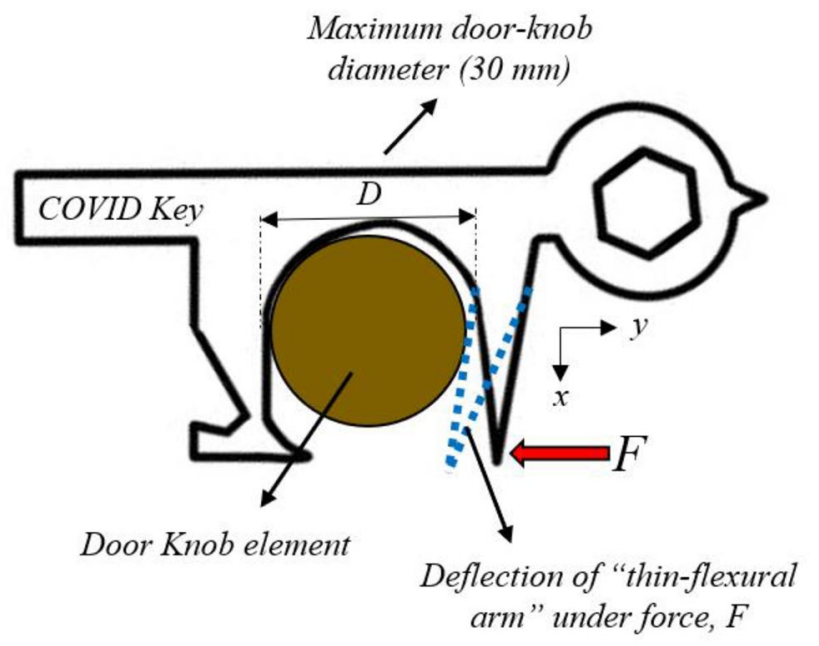

Fig. 7 Operation of "doorknob" feature of COVID key

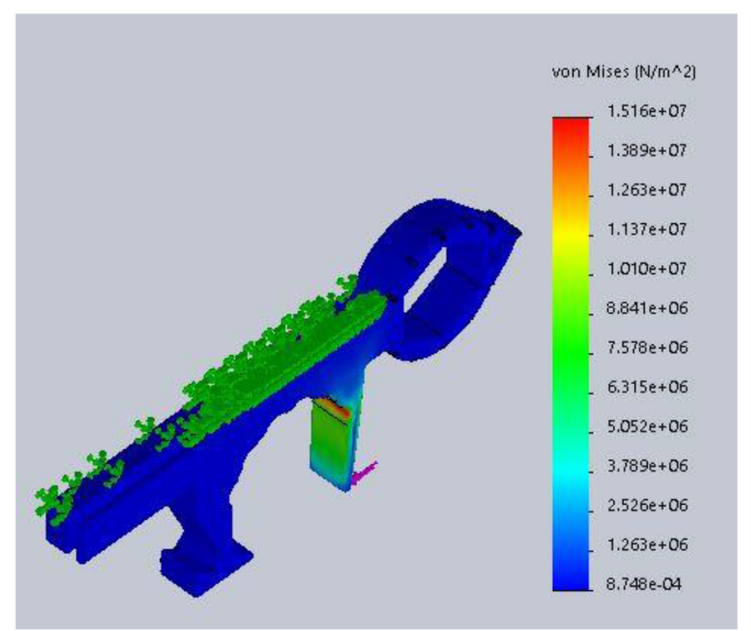

(a)

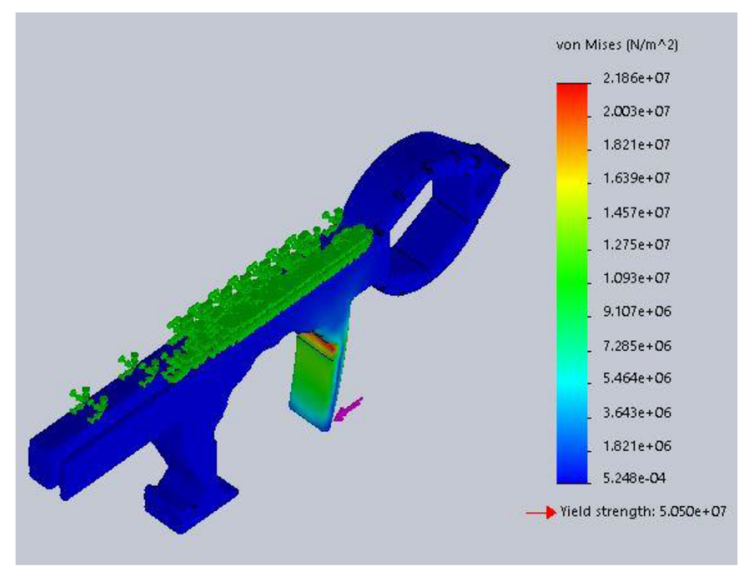

(c) $\sigma_{(\max )}=\frac{F}{A}+\frac{M \cdot y}{I}$

where $F$ is the pulling force $(100 \mathrm{~N}), A$ is the minimum cross-sectional area $(6 \mathrm{~mm} \times 10 \mathrm{~mm}), M$ is the generated bending moment along the neutral axis of the section, $y$ is the distance of the farthest fibre from the neutral axis ( $4 \mathrm{~mm})$, and $I$ is the area moment of inertia in the plane of cross-section $\left(\frac{10.8^{3}}{12} \mathrm{~mm}^{4}\right)$. The distance of the point of application of force from the neutral axis is $21 \mathrm{~mm}$, thereby generating a moment of $2.1 \mathrm{Nm}$. The maximum stress, calculated using Eq. (11), comes out to be $20.9375 \mathrm{MPa}$, which is within the elastic limit of the materials.

The deflection of the free end (i.e. strut region) can be calculated by assuming the COVID key as a cantilever beam subjected to a bending moment in between its length. Figure 9 depicts the mechanics modelling along with the

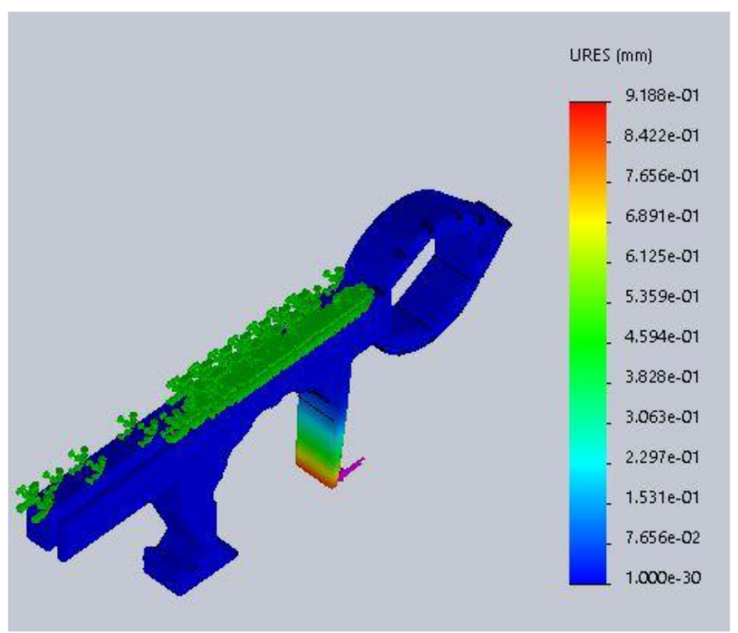

(b)

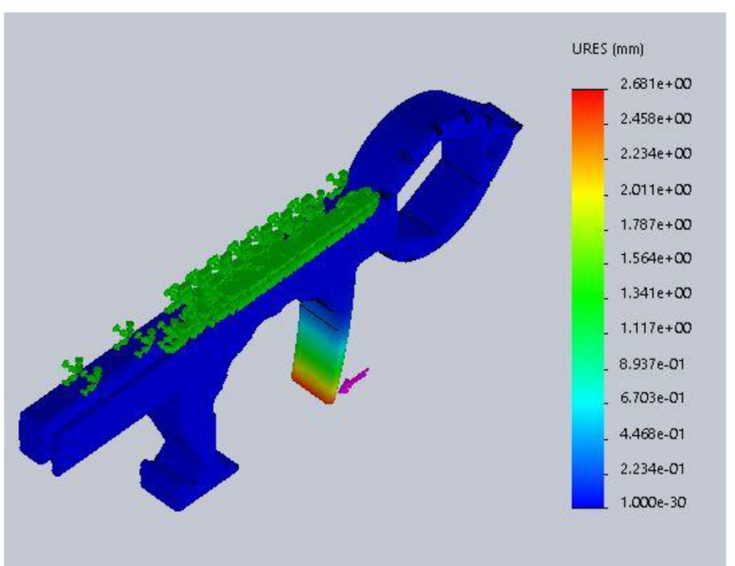

(d)

Fig. 8 FEA simulation of "door-knob" feature of COVID key: a stress distribution plot (ABS), b displacement plot (ABS), $\mathbf{c}$ stress distribution plot (PLA), d displacement plot (PLA) 


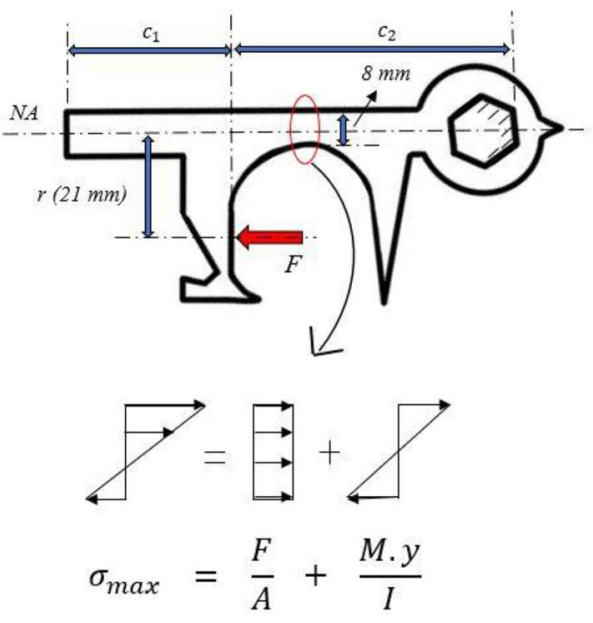

Fig. 9 Analysis of the "door-opener" feature

moment distribution and deflection diagram. The maximum deflection is calculated using Eq. 12:

$\delta=\frac{M \cdot c_{2}}{E_{b} \cdot I}\left[c_{1}+\frac{c_{2}}{2}\right]$

where $c_{1}$ and $c_{2}$ are the distances of the point of application of moment from free-end and fix-end, respectively. For $c_{1}=35 \mathrm{~mm}$ and $c_{2}=65 \mathrm{~mm}$, the maximum deflection came out to be $6.042 \mathrm{~mm}$.

With a similar environment of fixture geometry and loading conditions, FEA analysis is done. Peak stress of approximately $19.58 \mathrm{MPa}$ is observed in the vicinity of the minimal cross-sectional area. The deflection of the free-end tip came out to be $6.608 \mathrm{~mm}$ for ABS and $14.262 \mathrm{~mm}$ for PLA. Both these values are in close relationship with the analytical solution. Figure 10 shows the computational results of stress and displacement distribution of the "pull/ door-opener" feature of the COVID key.

\section{Torsional analysis}

Few elements also underwent torsional loadings, such as the hexagonal wrench feature and the sharp edge tool for screwbased applications. The torsional element under analysis is assumed to be homogenous throughout. The COVID key is assumed to be a circular shaft with a centrally aligned hexagonal cavity for wrench-based applications. The force is not directly applied over the wrench area. However, the generated torque is considered for the analysis, which is assumed to be constant throughout the length of that section.

In the case of the sharp edge, the section does not present a uniform cross-section along the direction of loading. An asymptotic limiting torque approach is used in that case to

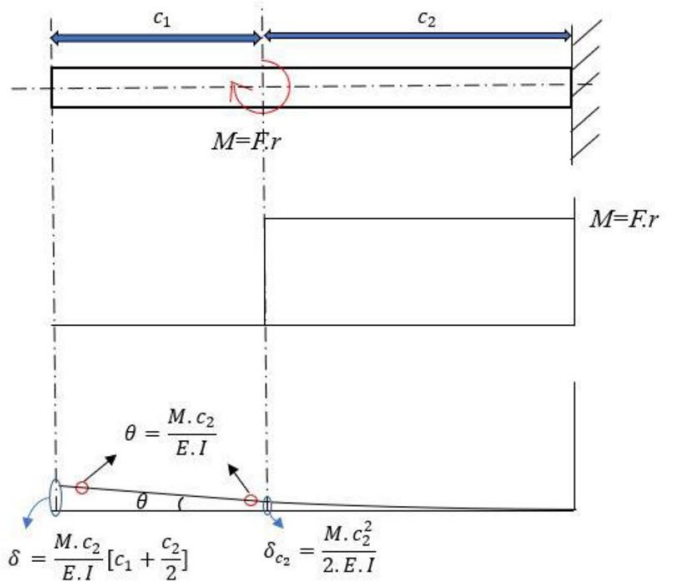

calculate the angular deformation and displacement fields. It is assumed that the area profile remains the same before and after torque application at any given cross-section. Only the relative orientation between the sections changed, i.e. radial lines remain radial during torsion (Grassia et al. 2011).

For wrench operations, within the range of $20 \mathrm{~mm}$, the hexagonal cut-out feature is given in the COVID key. The design is analysed for a maximum force of $100 \mathrm{~N}$ applied at the farthest section from the wrench area, i.e. the strut region. The linear separation between the point of application of force at the rotational centre of the wrench came out to be $110 \mathrm{~mm}$, generating a torque $(T)$ of $11 \mathrm{Nm}$. The maximum shear stress is developed at the outermost section of the wrench area, which is at a radial distance of $R=15 \mathrm{~mm}$. The generated shear stress $(\tau)$ at the periphery of the wrench area is calculated using Eq. (13) as follows:

$\tau=\frac{T \cdot R}{J}$,

where $(\tau)$ came out to be $2.891 \mathrm{MPa}$. The polar moment of inertia $(J)$ of the circular section, of outer diameter $(d=30 \mathrm{~mm})$ with a centrally aligned hexagonal cavity, of side length $(a=12 \mathrm{~mm})$ is given by Eq. (14).

$J=\frac{\pi}{32} d^{4}-\frac{5 \sqrt{3}}{8} a^{4}$

The last design feature of the COVID key is the sharp edge, which can be used for screw actions under the impact of torque. The sharp edge is a triangular prism section, $2 \mathrm{~mm}$ wide $(D), 2 \mathrm{~mm}$ long $(H)$ and $8 \mathrm{~mm}$ thick $(B)$, present at the end of the COVID key. For screwing action, the torque can be conveniently applied over the wrench area, with radially opposite sides in contact with the user's finger. The torque rating for a maximum applied force of $100 \mathrm{~N}$ at the wrench 


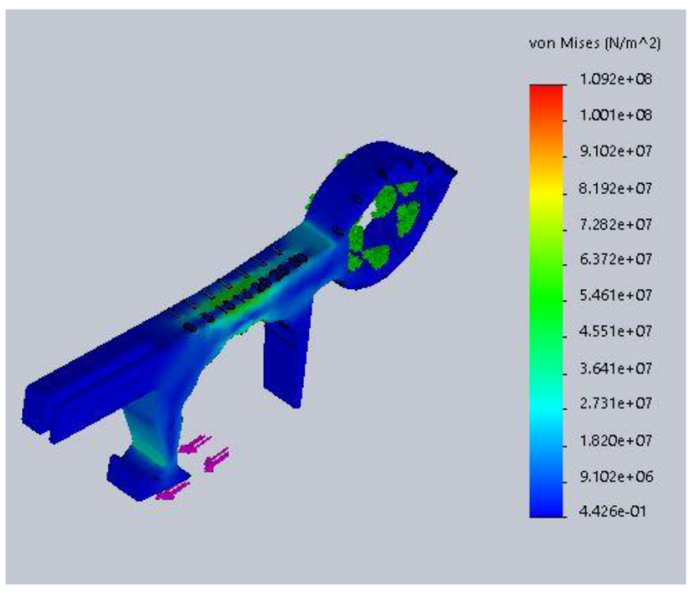

(a)

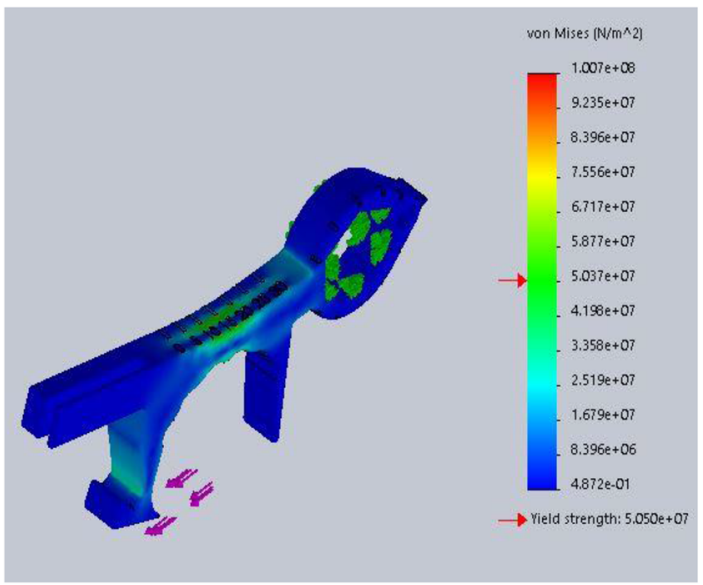

(c)

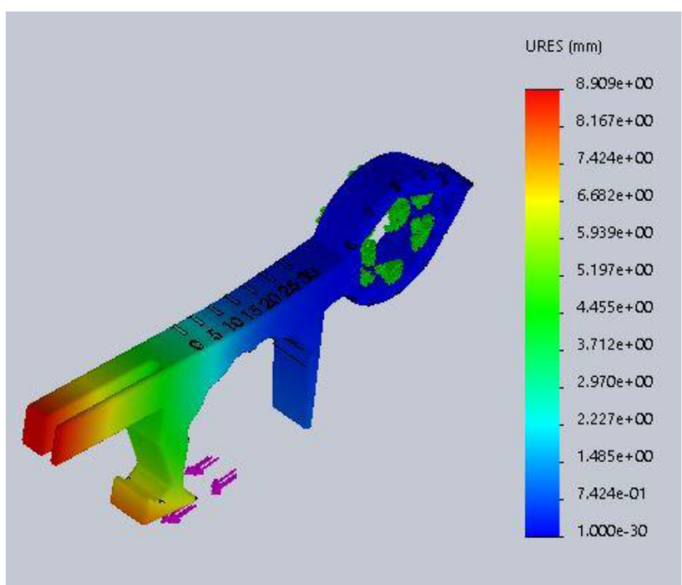

(b)

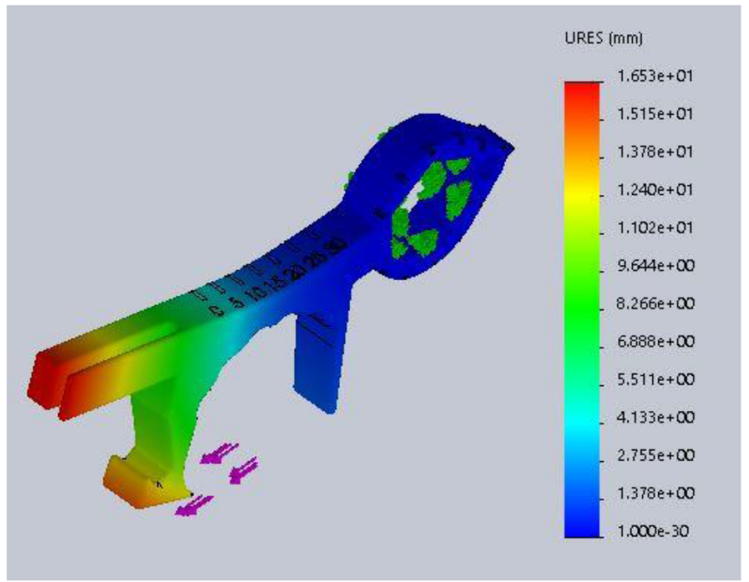

(d)

Fig. 10 "Door-opener" feature analysis: a stress distribution (ABS), b displacement plot (ABS) c stress distribution (PLA), d displacement plot (PLA)

area is $3 \mathrm{Nm}(2 \times 100 \mathrm{~N} \times 15 \mathrm{~mm})$. The cross-section of the sharp edge varies linearly from $(2 \mathrm{~mm} \times 8 \mathrm{~mm})$ at the fixed end to theoretically a line element, $8 \mathrm{~mm}$ long at the free end, as shown in Fig. 11. As the section presents a non-uniform cross-section, the conventional approach for torsional analysis and deflection cannot be used.
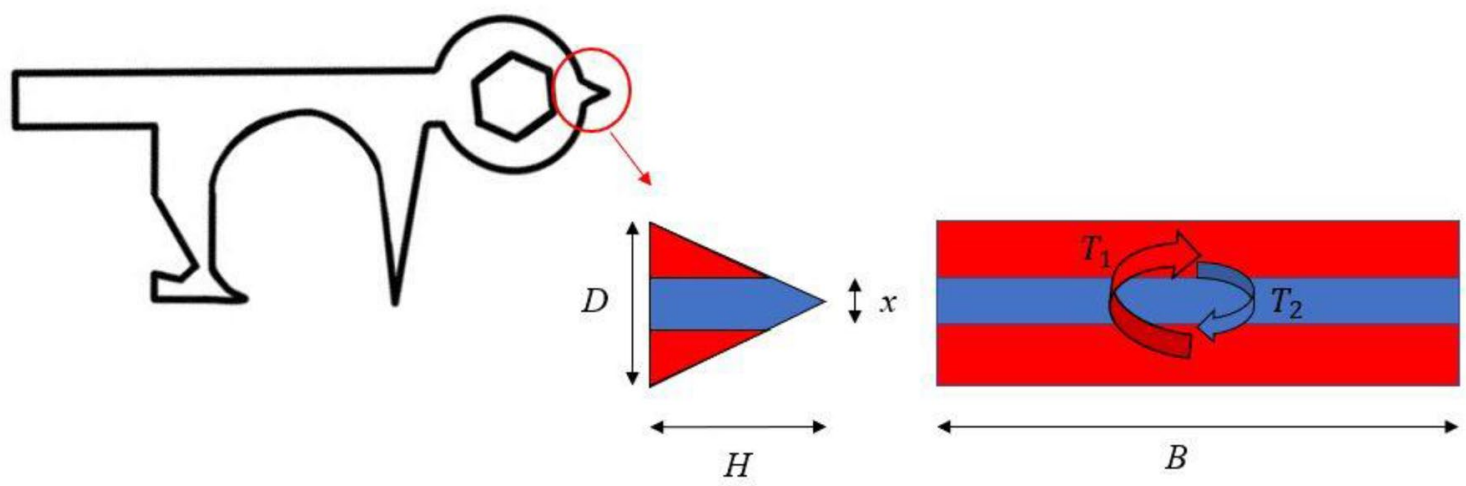

Fig. 11 Asymptotically limiting torque approach for "sharp edge" feature 
An asymptotically limiting torque approach is applied to solve the problem, where the section under torque is divided into two units, one of which is infinitesimally narrow $(x \rightarrow 0)$. These units have two different corresponding torque, adding up to the total applied torque. The ratio of the unit's torque is considered to be in proportion to the mass of individual units, which narrows down to the lateral areas of the unit. Mathematically,

$T=T_{1}+T_{2}, \frac{T_{1}}{T_{2}}=\frac{\text { Red Area }}{\text { Blue Area }}=\frac{2 \cdot\left(\frac{1}{2}\right) \cdot\left(\frac{D-x}{2}\right)\left(H-\frac{H \cdot x}{D}\right)}{x \cdot H} \approx \frac{D}{2 \cdot x}$

The torque in the broad region $\left(T_{1}\right)$ deforms the material along the twist direction $(\theta)$ which is set by the narrow region torque $\left(T_{2}\right)$. Solving Eq. (15) for the narrow region torque yields $T_{2} \simeq \frac{2 . T . x}{D}$ which when combined with the torsional properties provides the maximum linear deformation $(\delta)$ as follows:

$\delta=\theta \cdot \frac{B}{2}=\frac{T_{2} \cdot H \cdot B}{2 \cdot J \cdot G}=\frac{12 \cdot T \cdot H}{G \cdot D \cdot B^{2}}$,

where $G$ is the shear modulus of the material. The maximum linear deflection came out to be $0.88 \mathrm{~mm}$ for ABS and $0.257 \mathrm{~mm}$ for PLA at the free end tip. The shear stress at the fixed end, near the root, calculated using Eq. (13), came out to be $66.17 \mathrm{MPa}$.

FEA simulation of the sharp edge feature is done under the similar loading conditions mentioned above. A maximum deflection at the free end and peak stress at the root section of $0.55 \mathrm{~mm}$ and $65.13 \mathrm{MPa}$ for ABS; and $0.39 \mathrm{~mm}$ and $66.75 \mathrm{MPa}$ for PLA is observed, respectively. The stress and displacement distributions for both materials are shown in Fig. 12.

\section{Topology Optimization}

A topological optimization simulation analysis is also done on the COVID key design to get the optimal output subjected to specific constraints. The design is loaded with the previous mentioned forces and torques, subjected to appropriate fixtures. The optimization is set to a displacement constraint of the peak value of $15 \mathrm{~mm}$ at any given section. A goal of $10 \%$ mass reduction is also set. The peak stress is set to $65 \mathrm{MPa}$, as the Von-Mises limit of tensile and shear yielding. The set value is the minimum of both the materials, thereby innately saving both the materials. A $25 \%$ factory of safety $(\mathrm{FoS})$ is used for calculating the peak stress using Eq. (17),

$\sigma_{V M}=$ FoS. $\sqrt{\frac{1}{2}\left(\left(\sigma_{x}-\sigma_{y}\right)^{2}+\left(\sigma_{y}-\sigma_{z}\right)^{2}+\left(\sigma_{z}-\sigma_{x}\right)^{2}+6\left(\tau_{x y}^{2}+\tau_{y z}^{2}+\tau_{z x}^{2}\right)\right)}$
Manufacturing controls are also added to preserve selected regions of scale marking, keyholes and features like a bottle opener. To limit the simulation, thickness control is set if a section is going beyond the minimum limit of $2.15 \mathrm{~mm}$. A die-mould control and a symmetry control are also added to set the demoulding direction (as used in injection moulding) and a half symmetry plane.

The results obtained from the optimization are shown in Fig. 13. As the major section of the design is depicted in yellow (must keep section), the generated design is the optimized design.

\section{D Printing}

The designed COVID key has many intricate features such as overhangs, fillets, slender parts, and holes. Therefore, an additively manufactured route using $3 \mathrm{D}$ printing is considered the best direction for its manufacturing. The presented design is 3D printed using ABS and PLA materials on an FDM 3D printer. Three different orientations of the part are possible relative to the built platform. In each orientation, there is the presence of overhanging structures, which requires support generation. The horizontal orientation with minimum support generation is chosen for $3 \mathrm{D}$ printing. Different orientation along with their support volume usage is shown in Table 2. The part is oriented horizontally and deposited layer-by-layer with layer height set to $0.254 \mathrm{~mm}$ for optimized strength, surface finish and fabrication time (Mazzanti et al. 2019).

Open source software, Ultimaker Cura $\odot$, is used for slicing and gcode preparation. The commercially available FDM 3D printer, Creality Ender 3 ( ), is used for prototyping. The print conditions are mentioned in Table 3.

The 3D printed parts, along with the various real-life applications of the COVID key, are shown in Fig. 14.

\section{User satisfaction study}

A group of ten unbiased individuals is selected for the user satisfaction study. The qualified 3D printed COVID keys as per the proposed design are distributed to all ten individuals. The individuals are first given the usage's demo and then asked to use the key for their everyday activities mentioned in sections 1 and 2 for 15 days. On the 16th day, they are asked to evaluate their experience on the 10-point rating scale against six evaluation metrics, viz. ease of use, size, strength, appearance, material and ease of carrying. The results are mentioned in Table 4 and Fig. 15. 


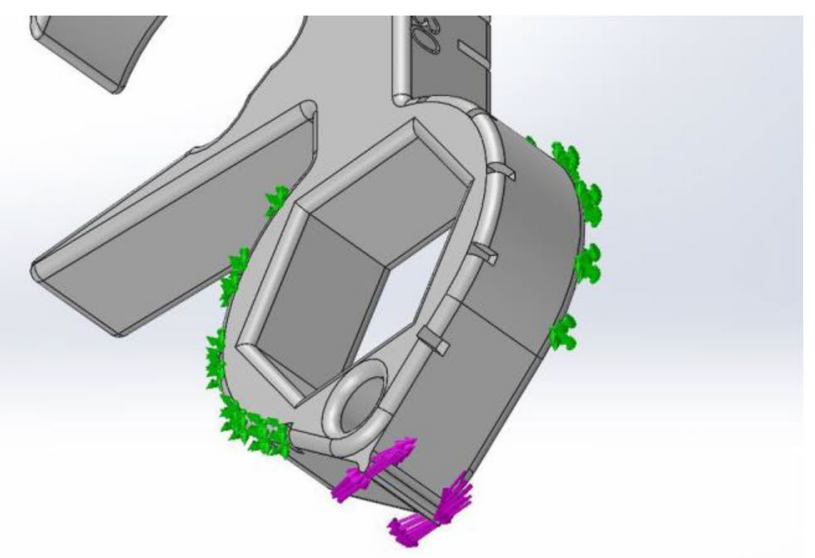

(a)

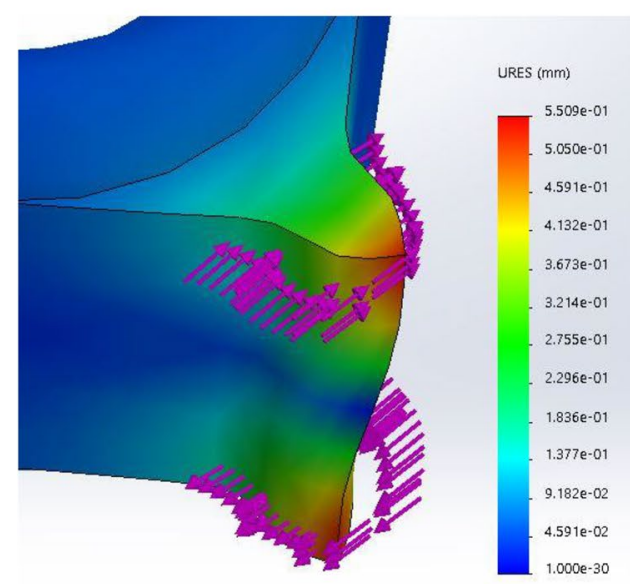

(b)

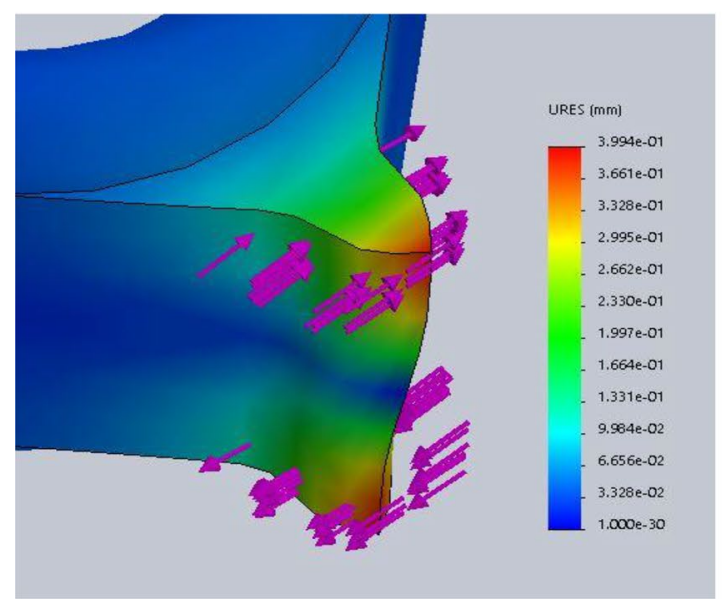

(d)

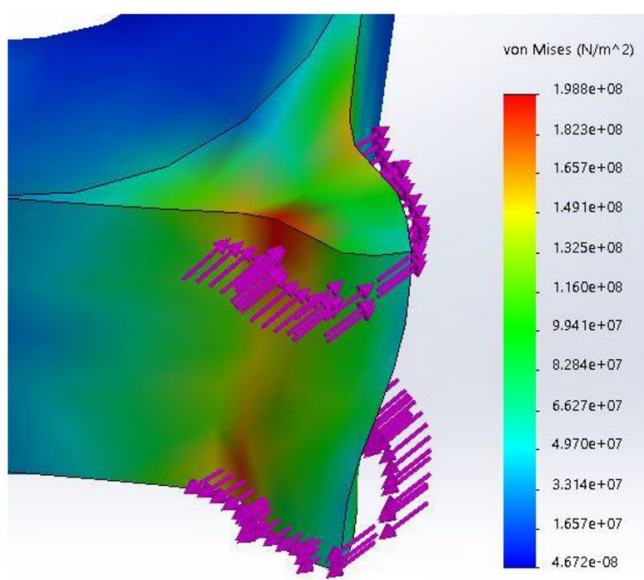

(c)

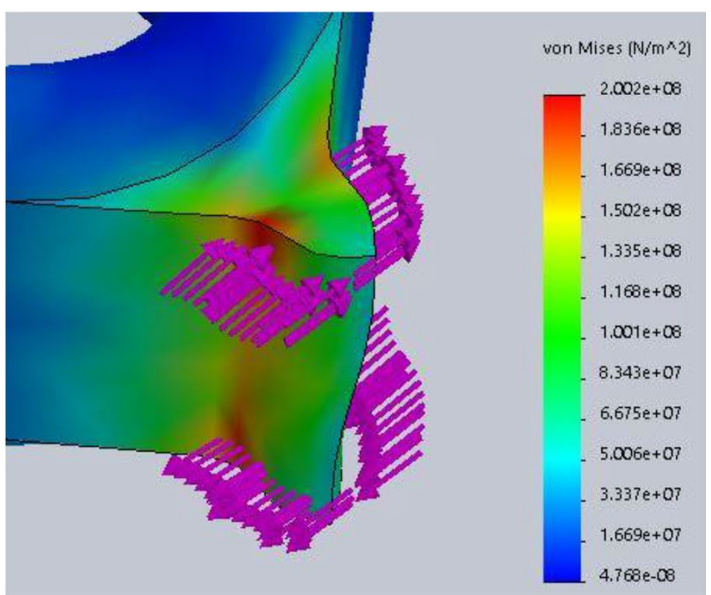

(e)

Fig. 12 Torsional analysis of "sharp edge" feature: a fixture geometry and loading condition, b displacement distribution (ABS), c stress distribution (ABS), $\mathbf{d}$ displacement distribution (PLA), e stress distribution (PLA) 


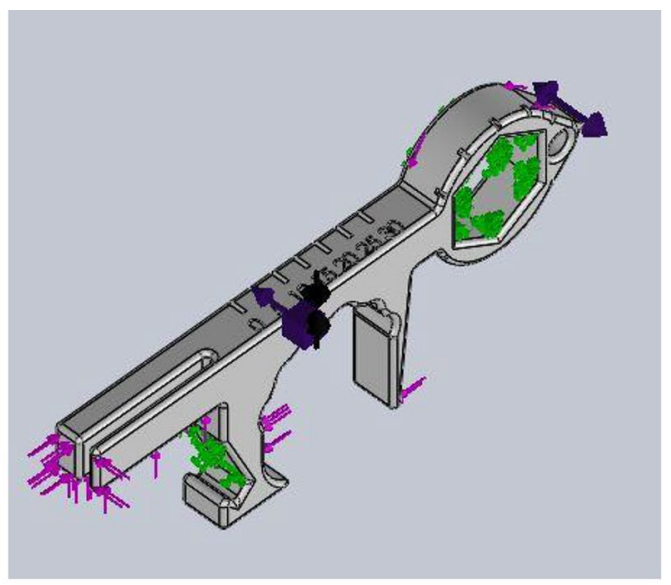

(a)

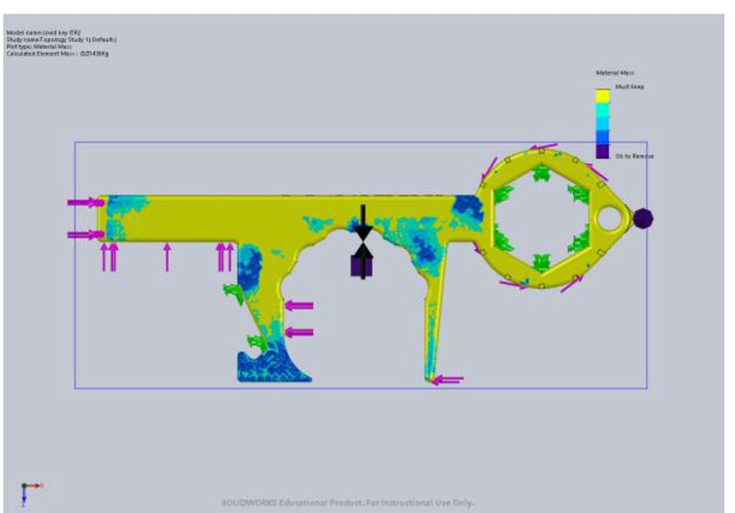

(b)

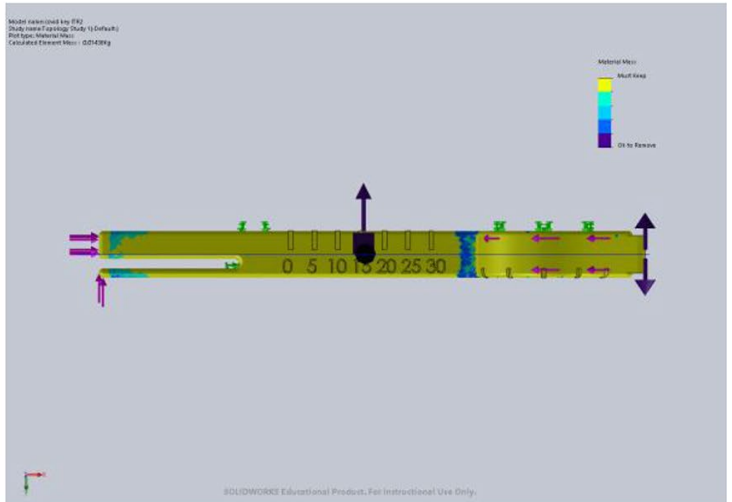

(c)

Fig. 13 Topology optimization: a COVID key design subjected to different constraints and loadings, $\mathbf{b}$ and $\mathbf{c}$ optimization results

\section{Economic analysis}

The present design of the COVID key has several features that incorporate intricate geometrical features and shapes. Additive Manufacturing (AM) using FDM 3D printing enables the production of the present COVID key with all its features without the need of special tooling. However, it is important to determine the production cost of the COVID key by the AM process.

\section{Cost analysis}

The cost has components as fixed and variable costs. The fixed costs are independent of the increase or decrease of the production volume whereas variable costs vary in proportion with the production volume. For AM applications, there is a linearity in the variable costs as well, thereby providing a constant cost per part (Costabile et al. 2017). The present article incorporates the FDM technique for the production of the COVID key. In the systematic calculation of the production costs for FDM systems there are several components such as pre-processing cost, material filament cost, machine depreciation cost, energy cost, consumables cost, post-processing cost and maintenance cost (Mello et al. 2010). There are several cost calculation approaches for AM depending on the production volume and the production strategy (Rosienkiewicz et al. 2018). AM technology enables to produce different parts simultaneously using the single build platform. However, in this analysis, multiple instances of the same geometry are printed on the build platform for productivity considerations. The same approach is used by Hopkinson and Dickens (Hopkinson and Dicknes 2003) that factors in the machine cost per part, labour cost per part and material cost per part to give the total cost per part (CPP) (Eq. 18).

$C_{\text {total }}=C_{\text {machine }}+C_{\text {labour }}+C_{\text {material }}$ 
Table 2 Different orientations and material consumptions for 3D printing in Ultimaker Cura

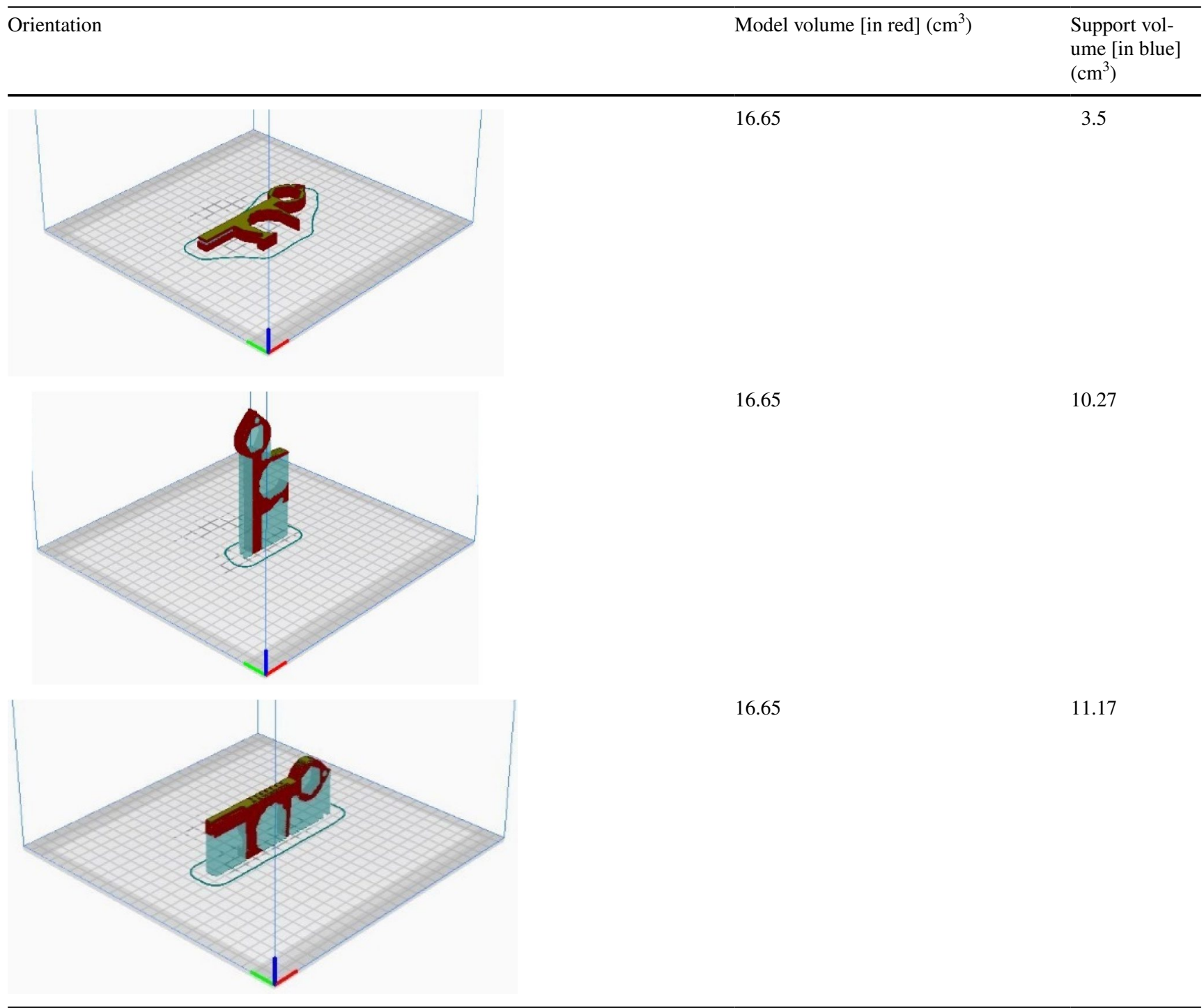

Table 3 Print conditions used in FDM 3D printing of the COVID key

\begin{tabular}{ll}
\hline Layer height & $0.254 \mathrm{~mm}$ \\
Infill & $100 \%$ \\
Print temperature & $230^{\circ} \mathrm{C}(\mathrm{ABS})$, \\
& $210^{\circ} \mathrm{C}$ \\
& $(\mathrm{PLA})$ \\
Build plate temperature & $60{ }^{\circ} \mathrm{C}$ \\
Print speed & $60 \mathrm{~mm} / \mathrm{s}$ \\
Support & Enabled \\
\hline
\end{tabular}

Three components are mainly machine cost per part ( $\left.C_{\text {machine }}\right)$, labour cost per part $\left(C_{\text {labour }}\right)$ and material cost per part $\left(C_{\text {material }}\right)$ that are added together to estimate the total cost per part $\left(C_{\text {total }}\right)$. The individual components are calculated by Eqs. (19), (20) and (21).
$C_{\text {machine }}=\left(\frac{\left(\frac{E}{8}\right)+M}{\frac{N H}{T}}\right)$

The machine cost per component $\left(C_{\text {machine }}\right)$ depends on machine equipment purchase cost $(E)$, maintenance cost per year $(M)$, number of components per build $(N)$, time of machine operation per year in hours $(H)$ and the time taken or completing one build $(T)$. Here, the depreciation period of the machine is considered as 8 years (Rosienkiewicz et al. 2018). Hence, the machine price is divided by 8 .

$C_{\text {labour }}=\left(\frac{W \times(S+P)}{N}\right)$ 


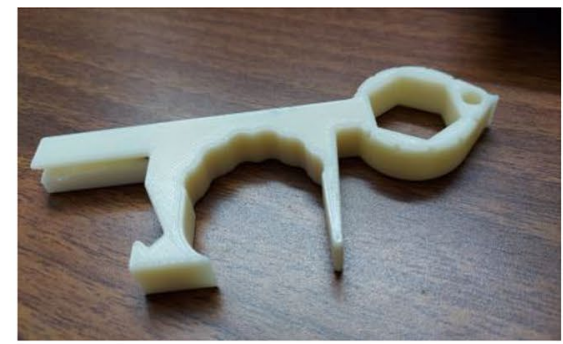

(a)

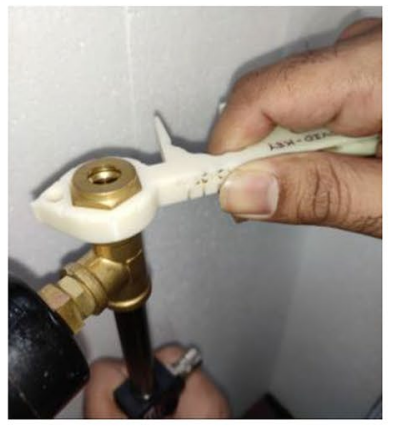

(c)

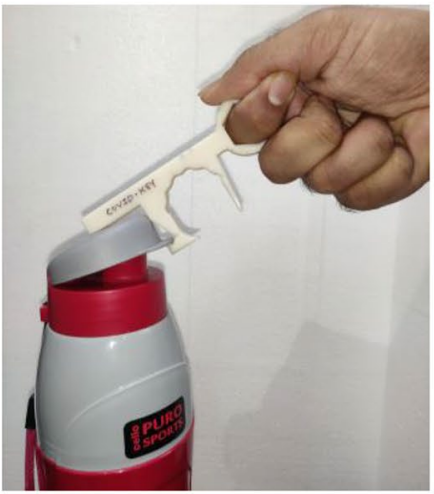

(f)

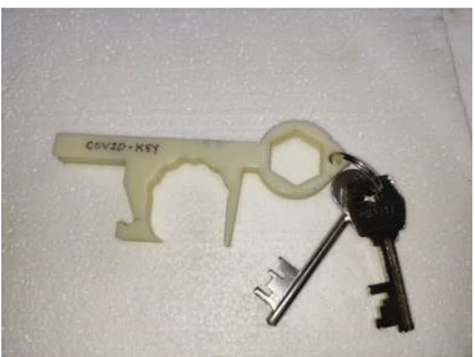

(i)

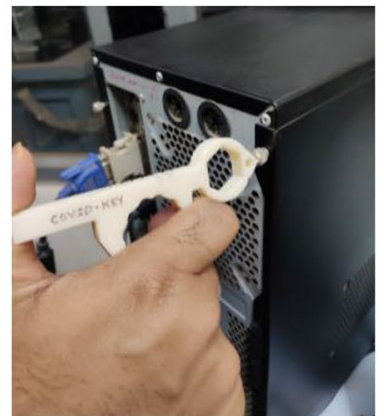

(d)

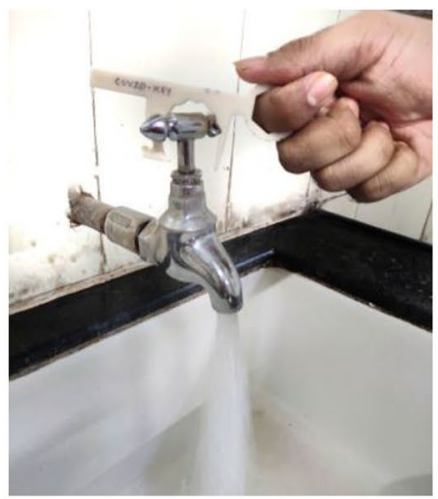

(g)

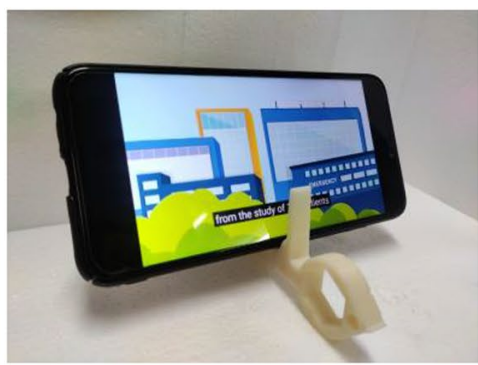

(j)

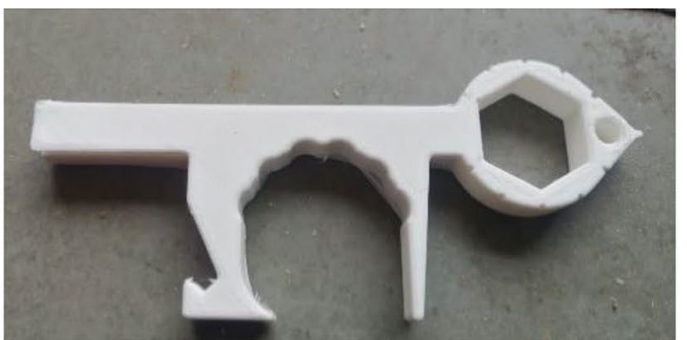

(b)

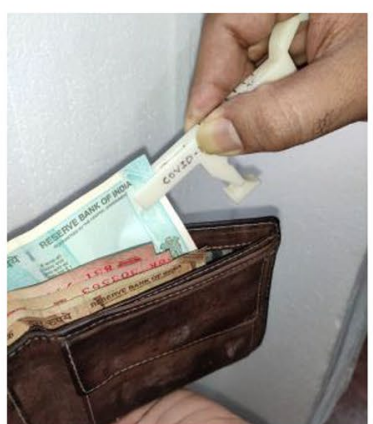

(e)

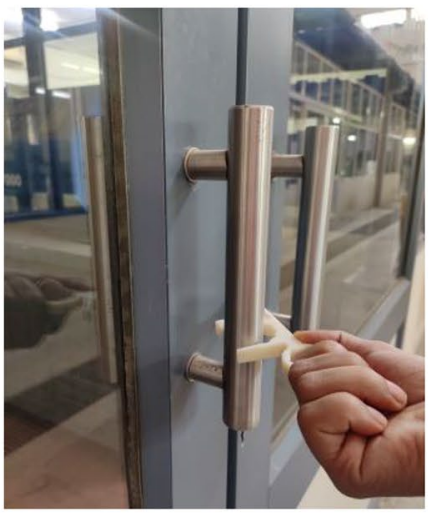

(h)

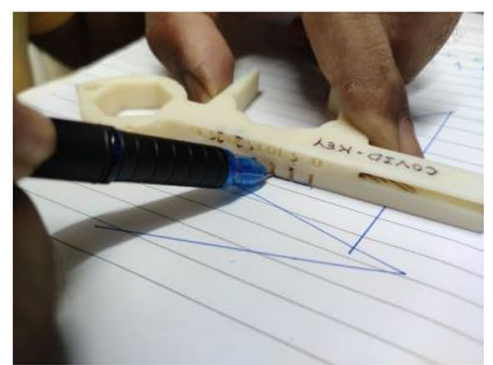

(k)
Fig. 14 Applications of COVID key: a 3D printed COVID key (ABS), b 3D printed COVID key (PLA), $\mathbf{c}$ wrench feature, $\mathbf{d}$ screw action using sharp edge, $\mathbf{e}$ forceps feature, $\mathbf{f}$ bottle opener feature, $\mathbf{g}$ operating water tap, $\mathbf{h}$ door opener feature, $\mathbf{i}$ as a key chain, $\mathbf{j}$ as a phone stand, $\mathbf{k}$ linear scale feature 
Table 4 User satisfaction study

\begin{tabular}{lllllll}
\hline Sr. no & Ease of use & Size & Strength & Appearance & Material & $\begin{array}{l}\text { Ease of } \\
\text { carry- } \\
\text { ing }\end{array}$ \\
\hline 1 & & & & & & 9 \\
2 & 8 & 8 & 9 & 10 & ABS & 9 \\
3 & 7 & 9 & 10 & 10 & ABS & PLA \\
4 & 9 & 7 & 8 & 9 & ABS & 5 \\
5 & 8 & 8 & 10 & 8 & PLA & 4 \\
6 & 10 & 8 & 10 & 8 & ABS & 9 \\
7 & 6 & 9 & 9 & 7 & ABS & 7 \\
8 & 7 & 9 & 9 & 9 & PLA & 8 \\
9 & 8 & 7 & 8 & 8 & ABS & 6 \\
10 & 5 & 8 & 7 & 10 & PLA & 9 \\
Average & 9 & 10 & 9 & 9 & ABS & 7.2 \\
Overall average & 8.18 & 8.3 & 8.9 & 8.8 & & \\
\hline
\end{tabular}

Fig. 15 Average user ratings for the COVID key design

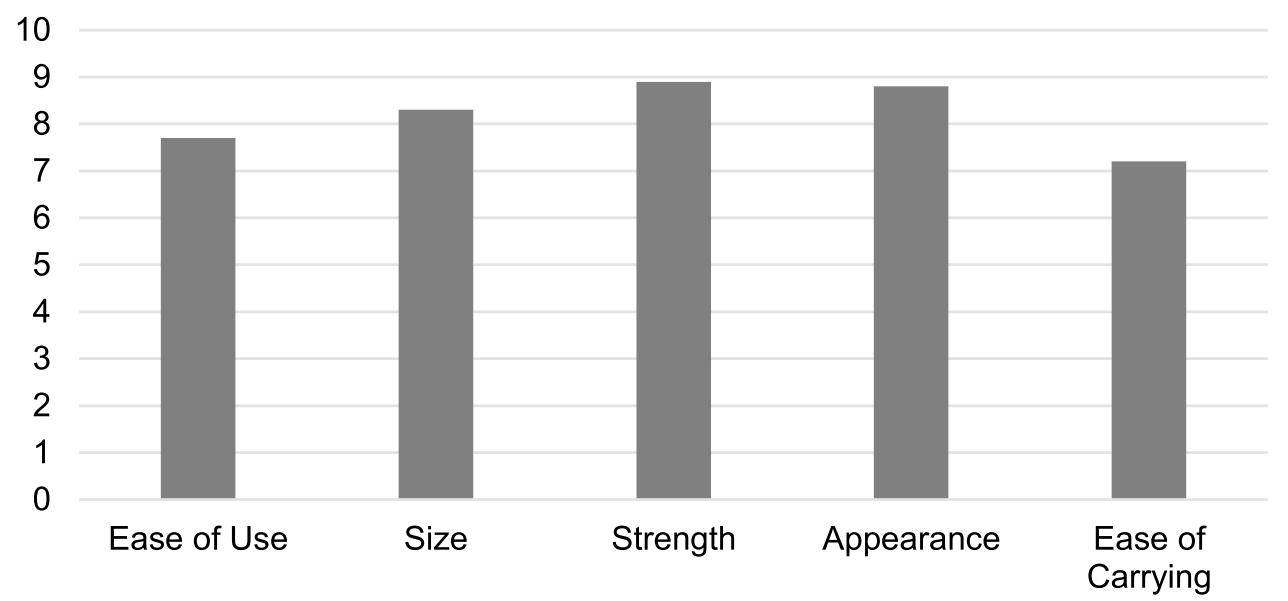

Averaged User Ratings
The labour cost per component $\left(C_{\text {labor }}\right)$ includes minimum hourly wages for the labour $(W)$, set up time for the machine control $(S)$, post-processing time $(P)$ and number of parts per build $(N)$.

$C_{\text {material }}=\left(M_{\text {model }} \times C_{\text {model }}\right)+\left(M_{\text {support }} \times C_{\text {support }}\right)$

Material cost per part ( $\left.C_{\text {material }}\right)$ for the FDM is calculated with the help of model material cost per $\mathrm{kg}\left(C_{\text {model }}\right)$, support material cost per $\mathrm{kg}\left(C_{\text {support }}\right)$, model material weight in $\mathrm{kg}$ $\left(M_{\text {model }}\right)$ and support material weight in $\mathrm{kg}\left(M_{\text {support }}\right)$.

For calculation of the specific prices, the minimum price range for each of the particular item is considered, as per Indian AM markets. The pricing with various 3D printing service bureaus and the widely used machines in the service bureaus are also discussed during the study. The machine under consideration for the cost analysis is the one that has been used, i.e. Creality Ender 3. It is widely used in the small sized $3 \mathrm{D}$ printing service bureaus and costs around (E) Rs. 15,000/- ( $200 \$ /-)$. The average maintenance cost per year $(M)$ is taken as Rs. 2,000/year ( 27 \$/year), which is approximately $13 \%$ of the equipment cost. The generic filaments of size $1.75 \mathrm{~mm}$ are considered with an average price of Rs. 1000/kg $(\sim 13.5 \$ / \mathrm{kg})$ for both ABS and PLA materials, after market research. With a bed area of $220 \mathrm{~mm} \times 220 \mathrm{~mm}$, a maximum of 7 COVID keys per built $(N)$ can be easily printed without difficulty, as shown in Fig. 16. The associated print time $(T)$ is estimated to be roughly $16 \mathrm{~h}$. Thereby, only one print, with full built platform, can be done in a single day. Considering that the machine runs for 300 days per year, the total working hours of machine operation per year $(H)$ came out to be $4800 \mathrm{~h} /$ year. Hence, the machine cost per part ( $C_{\text {machine }}$ ), using Eq. (19), came out to be the following: 


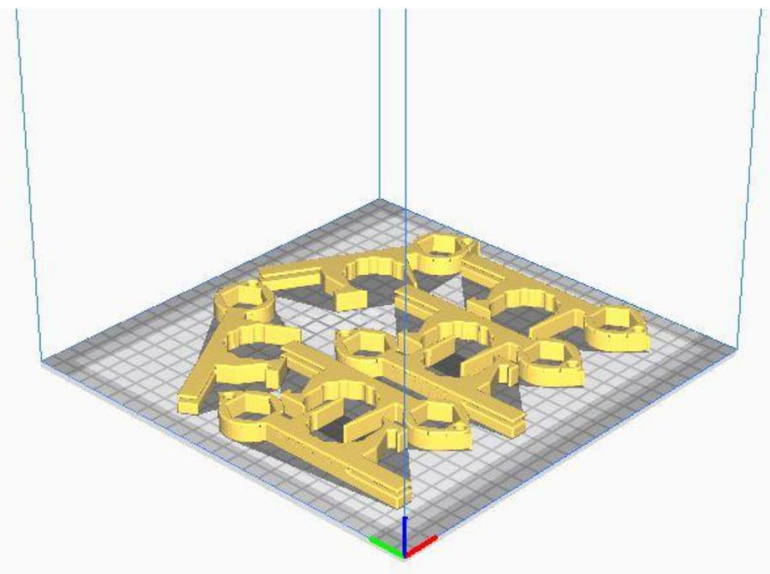

(a)

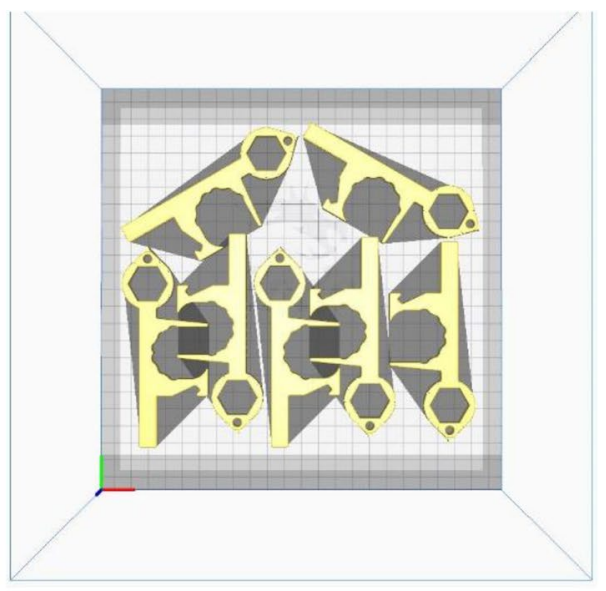

(b)

Fig. 16 Parts orientation over built plate, $\mathbf{a}$ isometric view, $\mathbf{b}$ top view

$C_{\text {machine }}=\left(\frac{\left(\frac{\text { Rs. } 15,000}{8 \text { years }}\right)+R s .2,000 / \text { year }}{\frac{7 \text { parts }}{\text { build }} \times 4,800 \frac{\text { hrs }}{\text { year }}}\right)=$ Rs. $1.845 /$ part

FDM 3D printers are totally automated machines, where the same set of commands (gcodes) can be used multiple times. A worker in a fabrication unit can start the FDM 3D printer in the morning. The set-up time for the machine $(S)$ is mainly affected by the heating time of the extruder, which is usually in the range of 3-4 min, depending upon the material and environmental conditions. After printing, the post-processing involves removal of support material. The parts are fabricated in the orientation with minimum support usage. Hence, in about 5-10 s per part $(P)$, the support material can be removed. In order to set an upper limit to the cost, the sum of setting-up and post-processing time $(S+P)$ is taken as $4 \mathrm{~min}$ and $10 \mathrm{~s}$, i.e. $250 \mathrm{~s}$ or $0.0694 \mathrm{~h}$. An hourly wage of Rs. 30/hr (Rs. 240 per day for an 8-h work day) is taken as the minimum wage $(W)$ in India for non-agricultural workers, involved in 3D printing industries (Litman et al. 2015). The labour cost per part ( $\left.C_{\text {labour }}\right)$, calculated using Eq. (20), came out to be the following:

$C_{\text {labour }}=\left(\frac{\text { Rs. } \frac{30}{\mathrm{hr}} \times(0.0694 \mathrm{hr})}{7 \text { parts }}\right)=$ Rs. $0.297 /$ part

Creality Ender 3 is a single-extruder FDM 3D printer, where the same material (ABS or PLA) is used for both model and support, i.e. $C_{\text {support }}=C_{\text {model }}$, for a given material. Therefore, the total volume consumption, including model and support, per part is $20 \mathrm{~cm}^{3}$, which is equivalent to $20.4 \mathrm{~g} \mathrm{ABS}$ or $26.4 \mathrm{~g}$ PLA. Hence, the material cost per part $\left(C_{\text {material }}\right)$ is as follows:

$$
\begin{aligned}
C_{\text {material }} & =C_{\text {model }} \times\left(M_{\text {model }}+M_{\text {support }}\right) \\
& =\text { Rs. } \frac{1000}{k g} \times(0.0204 \mathrm{~kg}(\mathrm{ABS}) \text { or } 0.0264 \mathrm{~kg}(\mathrm{PLA})) \\
& =\text { Rs. } 20.4 / \text { part }(\mathrm{ABS}) \text { or Rs. } 26.4 / \text { part }(\mathrm{PLA})
\end{aligned}
$$

The overall cost per part is the summation of the cost components calculated in Eqs. (22), (23) and (24). A tabular description of the same is given Table 5.

From the table above, it can be seen that it is more economical $(\sim 26.6 \%)$ to go with ABS material for COVID key production.

\section{Breakeven analysis}

A breakeven analysis is also done to determine the breakeven point and time to breakeven. Breakeven point is the minimum number of units $(U)$ (in this case COVID keys) that needs to be sold to cover the costs. In order to generate a profit, a minimum of breakeven units has to be sold, as breakeven is the point of zero-profit. The time, in terms of

Table 5 Comparative analysis of the price of COVID key

\begin{tabular}{ll}
\hline Cost component & Specific cost (Rs. /part) \\
\hline Machine & 1.845 \\
Labour & 0.297 \\
Material & 20.4 (ABS), 26.4 (PLA) \\
Total Cost Per Part (CPP) & 22.54 (ABS), 28.54 (PLA) \\
\hline
\end{tabular}


economic/working days needed to achieve breakeven point is the time to breakeven.

A total cost function (TCF) is defined which is the sum of the fixed cost and variable cost. The fixed cost is taken as the equipment cost $(E)$ and the overhead cost $(O)$. The variable cost is defined as the cost per part fabricated. As ABS is more economical than PLA, Rs. 22.54/part is taken as the variable cost. With an overhead $(O)$ of $40 \%$, the total cost function is given in Eq. (25).

$\mathrm{TCF}(U)=E \times\left(1+\frac{O}{100}\right)+\mathrm{CPP}=$ Rs. $(21,000+22.54 \times U)$

A through market research brought the price in the range of Rs. 70-150. We have considered a competitive price of Rs. 60 with approximately $167 \%$ profit margin $\left(P^{*}\right)$. Hence, a revenue function (RF) is set as Eq. (26).

$\operatorname{RF}(U)=\operatorname{CPP}(U) \times\left(1+\frac{P^{*}}{100}\right)=$ Rs. $60 \times U$

To determine the breakeven point, the revenue generated should be surpass the total expenditure. Mathematically, Eq. (27) has to be satisfied for breakeven.

$\mathrm{TCF}<\mathrm{RF}$

Solving the above equation for number of units $(U)$, the breakeven point came out to be 561 units, i.e. after $561^{\text {st }}$ unit profit will be generated and the fixed cost will be covered.

Graphically, the point of intersection between $R F$ and $T C F$, on the $\mathrm{x}$-axis, gives the breakeven point, as shown in Fig. 17.
With an average production of 7 parts per day, it will take 80 days to reach breakeven. Multiple 3D printers can be simultaneously loaded to reduce the delay in breakeven.

\section{Conclusions}

Different case studies highlighting the multifunctionality of the presented design of the COVID key are reflected in this work. The detailed FEA analysis shows that the present COVID key is fit to be used in domestic and workplace settings. The prime application for the given COVID key is in the hospital buildings with a high number of people living or being treated for COVID. All majority actions such as pushing, pulling, pinching, tightening, measuring and holding can be performed satisfactorily with the present COVID key. Additively manufactured key from ABS plastic has the necessary strength and aesthetics to be operated as per the directions and is more economical from PLA, from manufacturing point of view. Extensive use of the key found that the actions can be performed swiftly with some practice. A user satisfaction study based on the six essential metrics found that users rate the most for the strength of the given key with a maximum of 8.9 ratings. The ratings for appearance, size, ease of use and ease of carrying are 8.8, 8.3, 7.7 and 7.2 respectively. The overall satisfaction rating is 8.18 , and the preferred material is ABS.

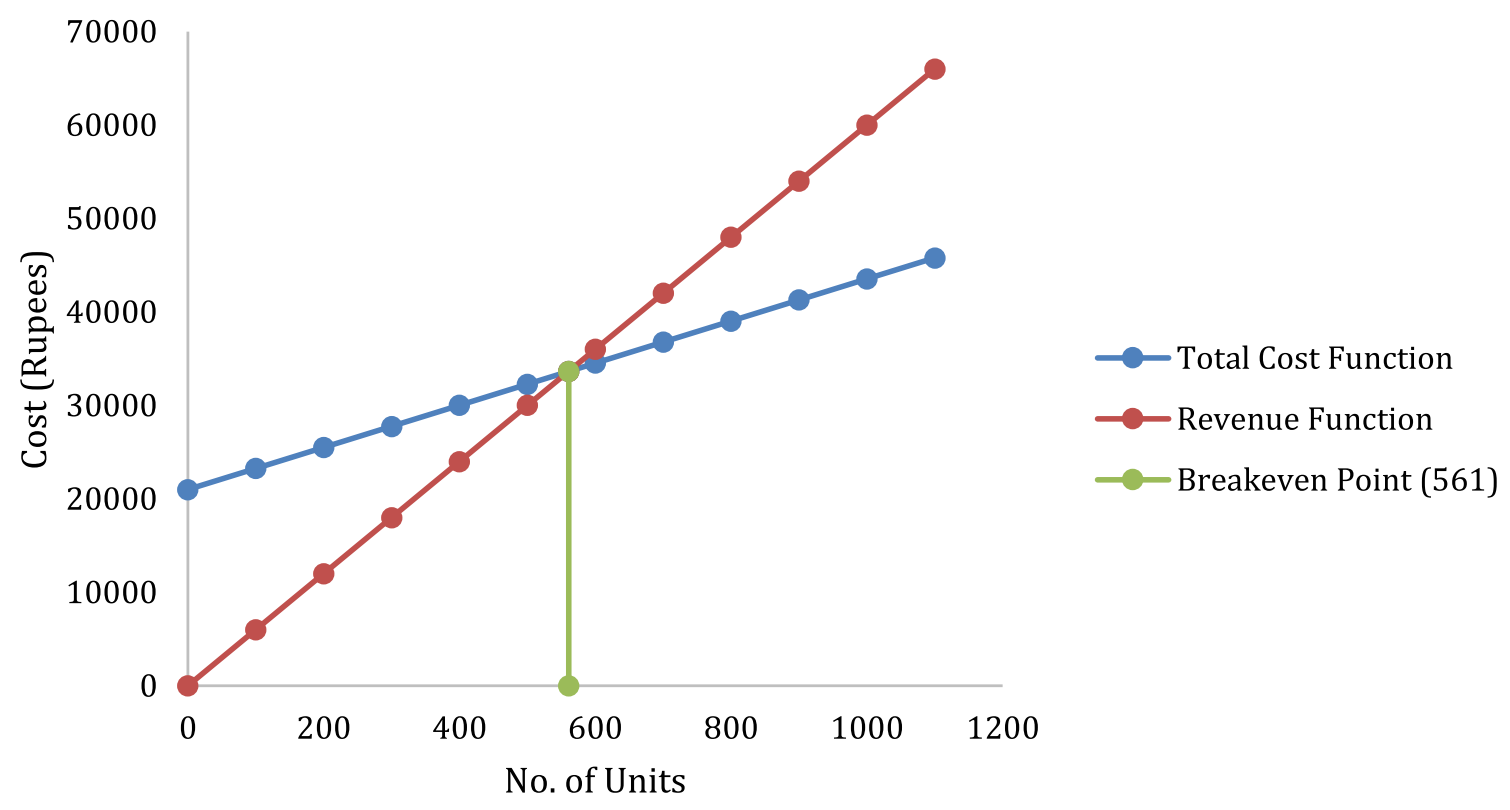

Fig. 17 Breakeven analysis 


\section{Merits}

- A novel key design that gives good protection against infectious surfaces by enabling a remote touch.

- Multifunctionality of the key enables the user to perform various actions and reduces the need to carry multiple tools to perform a wide range of actions.

- The size of the key is compact; hence it can be stored in the pockets, handbags and purse after proper sanitization.

- The geometry is simplified to make it suitable for 3D printing where the CAD model can be shared with people. It can be printed from the nearby 3D printing facility. It makes the distribution of the key easy and widespread.

\section{Demerits}

- It could be troublesome to use the key initially due to a lack of experience in using it. Thus, the authors suggest using the key repeatedly to get accustomed to social settings.

- Key is not suitable for some very specific or extreme applications with size and temperature constraints. However, the design and material can be modified to suit the particular application.

\section{References}

Abeykoon C, Sri-Amphorn P, Fernando A (2020) Optimization of fused deposition modeling parameters for improved PLA and ABS 3D Printed Structures. Int J Lightweight Mater Manuf 3(3):284-297

Banjanin B, Gojko V, Magdolna P, Sebastian B, Miroslav D, Milan R, Ivan K (2018) Consistency analysis of mechanical properties of elements produced by FDM additive manufacturing technology. Matéria (rio De Janeiro). https://doi.org/10.1590/s1517-70762 0180004.0584

Bhardwaj R, Agrawal A (2020) Likelihood of survival of coronavirus in a respiratory droplet deposited on a solid surface. Phys Fluids 32(6):061704

Bourouiba L (2020) Turbulent gas clouds and respiratory pathogen emissions: potential implications for reducing transmission of COVID-19. J Am Med Assoc 323(18):1837-1838

Cantrell JT, Rohde S, Damiani D, Gurnani R, DiSandro L, Anton J, Young A (2017) Experimental characterization of the mechanical properties of 3D-printed ABS and polycarbonate parts. Rapid Prototyp J 3:89-105 \&

Costabile G, Fera M, Fruggiero F, Alfredo L, Duc P (2017) Cost models of additive manufacturing: a literature review. Int J Ind Eng Comput 8(2):263-283
Ferreira RT, Amatte IC, Dutra TA, Bürger D (2017) Experimental characterization and micrography of 3D printed PLA and PLA reinforced with short carbon fibers. Compos Part B 124:88-100

Grassia L, Carbone MGP, Mensitieri G, D'Amore A (2011) Modeling of density evolution of PLA under ultra-high pressure/temperature histories. Polymer 52(18):4011-4020

Hopkinson N, Dicknes P (2003) Analysis of rapid manufacturingusing layer manufacturing processes for production. Proc Instit Mech Eng Part C 217(1):31-39

Jean-Philippe C, Qaiyumi A, Rodriguez U, Arroyo AA, Schwartz (2002) Autonomous Bottle Opener Robot. University of Florida, Department of Electrical and Computer Engineering, Intelligent Machines Design Laboratory EEL 5666. https://mil.ufl.edu/5666/ papers/IMDL_Report_Spring_02/jean-philippe_clerc/abor.pdf

Litman L, Robinson J, Rosenzweig C (2015) The relationship between motivation, monetary compensation, and data quality among USand India-based workers on Mechanical Turk. Behav Res Methods 47(2):519-528

Mazzanti V, Malagutti L, Mollica F (2019) FDM 3D printing of polymers containing natural fillers: a review of their mechanical properties. Polymers 11(7):1094

Mello CBHP, Martins RC, Parra BR, De Oliveira EP, Salgado EG, Seguso RT (2010) Systematic proposal to calculate price of prototypes manufactured through rapid prototyping an FDM 3D printer in a University Lab. Rapid Prototyp J 16(6):411-416

Nilsen T, Hermann M, Eriksen CS, Dagfinrud H, Mowinckel P, Kjeken I (2012) Grip force and pinch grip in an adult population: reference values and factors associated with grip force. Scand J Occup Ther 19(3):288-296

Richard JKN, Budynas G (2011) Shigley's mechanical engineering design, 9th edn. Mcgraw Hill, New York

Rosienkiewicz M, Gabka J, Helman J, Kowalski A, Susz S (2018) Additive manufacturing technologies cost calculation as a crucial factor in industry 4.0. Lecture notes in mechanical engineering. Springer, Cham, pp 171-183

Song Y, Li Y, Song W, Yee K, Lee KY, Tagarielli VL (2017) Measurements of the mechanical response of unidirectional 3D-printed PLA. Mater Des 123:154-164

Stephen JMG, Timoshenko P (1961) Theory of Elastic Stability, 2nd edn. McGraw Hill, London

Torres J, Cotelo J, Karl J, Gordon AP (2015) Mechanical property optimization of FDM PLA in shear with multiple objectives. JOM 67(5):1183-1193

Vácha J, Borůvka M (2015) Mechanical properties of acrylonitrile butadiene styrene thermoplastic polymer matrix with carbon nanotubes. In: NANOCON 2015, 7th International Conference on Nanomaterials Research and Application, pp 132-137

Wang C, Horby PW, Hayden FG, Gao GF (2020) A novel Coronavirus outbreak of global health concern. Lancet 395(10223):470-473

WHO (2020) Modes of transmission of virus causing COVID-19: implications for IPC precaution recommendations. WHO, Geneva, pp 19-21

Wittbrodt B, Pearce JM (2015) The effects of PLA colour on material properties of 3-d printed components. Addit Manuf 8:110-116

Publisher's Note Springer Nature remains neutral with regard to jurisdictional claims in published maps and institutional affiliations. 